\title{
Development of Binocular Vision in the Kitten's Striate Cortex
}

\author{
Ralph D. Freeman and Izumi Ohzawa \\ Group in Neurobiology, School of Optometry, University of California at Berkeley, Berkeley, California 94720
}

Studies of the development and plasticity of the visual pathway are well documented, but a basic question remains open: what is the physiological status of the system prior to extensive visual experience? Somewhat conflicting answers have been put forward, and in a major area, binocular vision, reports have ranged from severe immaturity to well-developed maturity. This is an important question to resolve since binocular cells in the visual cortex are thought to be the neural substrate for stereoscopic depth perception.

We have addressed this question by recording from single cells in the striate cortex of kittens at postnatal ages 2, 3, and 4 weeks and from adults for comparison. Gratings with sinusoidal luminance distribution are presented to left, right, or both eyes. For each cell, we determine optimal values for orientation and spatial frequency. Relative phase (retinal disparity) is then varied in a dichoptic sequence so that binocular interaction may be studied.

Results are as follows. In the normal adult, we have shown in previous work that most binocular interaction in the visual cortex can be accounted for on the basis of linear summation. Results from 3 and 4 week postnatal kittens are closely similar to those from adults. All types of binocular interaction found in adults are present in kittens. This includes phasespecific and non-phase-specific suppression or facilitation. Furthermore, monocular and binocular tuning characteristics are comparable in kittens and adults. The clear changes that occur with age are optimal spatial frequencies and peak responses. In addition, at 2 weeks, there is a substantially higher proportion of monocular cells compared to other ages and correspondingly, lower relative numbers of cells that exhibit phase-specific or suppressive binocular interactions.

From increases in optimal spatial frequency and interpupillary distance with age, we calculated predicted changes in binocular disparity thresholds (stereo acuity) with age. Although there are methodological limits with respect to the behavioral testing of young kittens, the predicted results are comparable to some of the values obtained. Considered together, our results show that the physiological apparatus for binocular vision is functional at an early stage in postnatal development. It is possible that the connections that underlie this function are developed rapidly during early postnatal experience. An alternative possibility is that there is an elaborate genetic organization of binocular vision, but our study does not address this issue directly. A combination of these

Received Mar. 4, 1992; revised June 16, 1992; accepted June 25, 1992.

This work was supported by research and CORE grants from the National Eye Institute (EY01175 and EYO3176) and by a collaborative project of the Human Frontier Science Program.

Correspondence should be addressed to Ralph D. Freeman, 360 Minor Hall, University of California, Berkeley, CA 94720.

Copyright (C) 1992 Society for Neuroscience $0270-6474 / 92 / 124721-16 \$ 05.00 / 0$ factors may be applicable. In any case, although major refinements occur in stereoscopic vision postnatally, the physiological connections that underlie this function are operational at a very early postnatal age.

The development and plasticity of visual function has been studied extensively by use of behavioral, physiological, anatomical, and neurochemical approaches. This work has engendered a considerable literature, which is reviewed in several articles (see, e.g., Frégnec and Imbert, 1984; Mitchell and Timney, 1984).

In order to understand the limits and rules of plasticity, one requires firm knowledge of normal visual functions at various stages of development. By far the most studied animal in this work is the cat. At birth, a kitten's eyelids are sealed and optical quality of the eye is poor (Thorn et al., 1976; Freeman and I ai, 1978). However, optical function improves markedly during the first few postnatal weeks, and measurements of retinal image quality suggest that visual performance is not limited by this non-neural factor (Bonds and Freeman, 1978).

There is a somewhat surprising paucity of data on development of peripheral connections in the retina and LGN. Physiological studies of the retina of the kitten show that brisk visual responses of ganglion cells occur during the third postnatal week (Hamasaki and Flynn, 1977; Rusoff and Dublin, 1977). However, receptive fields are generally large, responses are weak, and antagonistic surrounds are poorly defined. These same characteristics have been observed in the case of the LGN (Daniels et al., 1978; Ikeda and Tremain, 1978).

Developmentally, most attention has been paid to the visual cortex. Physiological studies of cortical cells in kittens have resulted in a face-off of Nativist and Empiricist views. The Nativist notion is supported by the original work of Hubel and Wiesel (1963), who observed, from a small population of cells, that the main response properties found in adult cortex, that is, direction and orientation selectivities, and binocularity, were also present in the visually inexperienced cortex of kittens. The Empiricist concept is invoked by the reports of Barlow and Pettigrew (1971) and Pettigrew (1974), who noted that the cortical cells of visually inexperienced kittens did not exhibit stimulus specificity. Although some subsequent reports suggest positions between the two extreme views (e.g., Blakemore and Van Sluyters, 1975; Fregnac and Imbert, 1978; Bonds, 1979; Derrington and Fuchs, 1981), more recent work tends to support the original claim of Hubel and Wiesel (1963) that the major elements of visual specificity are genetically programmed. They do not begin to deteriorate, in the event of visual deprivation in the kitten, until 3 or 4 weeks postnatal (Albus and Wolf, 1984; Braastad and Heggelund, 1985). However, beyond that period, deprivation causes deterioration of visual processes (see, e.g., Mitchell and Timney, 1984) and these may occur relatively quickly (e.g., Freeman et al., 1981; Freeman and Olson, 1982). 
It is clear, therefore, that normal visual experience is required for proper development of the visual system.

In all the studies noted above, the focus of attention has been on monocular properties of cells. Very little attention has been paid to the binocular system. An anatomical study of ocular dominance columns and their development in layer IV of the kitten's visual cortex suggests that column formation begins before 3 weeks of age and is adultlike at about 6 weeks (LeVay et al., 1978). The only physiological study of the development of binocular vision appears to be that of Pettigrew (1974). He found that binocular disparity selectivity was nearly entirely absent in postnatal weeks 2,3 , and 4 . Only in the fifth week does it appear and even then, the majority of cells do not exhibit binocular disparity selectivity (Pettigrew, 1974, his Fig. 8). This is a remarkable finding since it suggests that development of binocularity lags considerably behind that of the monocular system.

To clarify this issue, we have examined quantitatively the development of binocular vision in the kitten's striate cortex. We use a robust visual stimulation technique that employs large, bright gratings whose relative phase between the two eyes is varied to alter retinal disparity. Our results demonstrate that disparity-selective cells are as common in 3 and 4 week postnatal kittens as they are in adults. Even at 2 weeks, a substantial number of the cells that could be driven were disparity selective. Estimates of the width of tuning of disparity-selective cells show extensive overlap with those for adults. We conclude that the physiological facility for binocular disparity selectivity is present as early as one can effectively measure it. This suggests that it is a genetically programmed function that requires visual experience primarily for maintenance and refinement. We cannot rule out the possibility, however, that a considerable amount of neuronal development that is relevant to this function, occurs during an early postnatal period.

\section{Materials and Methods}

Animals. We studied 13 kittens in three age groups: 2 weeks postnatal (P14, i.e., $14 \mathrm{~d}$ after birth), 3 weeks postnatal (P21, i.e., $21 \mathrm{~d}$ after birth), and 4 weeks postnatal (P28, i.e., $28 \mathrm{~d}$ after birth). Recordings for all kittens were begun at the exact age or $1 \mathrm{~d}$ before or after. In this article, when we refer to 2,3 , or 4 week kittens, we mean that their physiological recordings were begun within $1 \mathrm{~d}$ of postnatal days 14,21 , or 28 , respectively. Data from 11 adult cats are also used for comparison. The kittens were reared in a laboratory colony of mixed-breed and Millhill cats. A daily cycle of $16 \mathrm{hr}$ light and $8 \mathrm{hr}$ dark was used in the colony. Animals were checked daily to make sure of general health and to ensure that eyes were not infected.

Physiological preparation. On the appropriate postnatal day, a kitten was premedicated prior to surgery by subcutaneous injection of a tranquilizer (acepromazine, $1 \mathrm{mg} \cdot \mathrm{kg}^{-1}$ ) and a cholinergic blocker to reduce secretion (atropine, $0.2 \mathrm{mg} \cdot \mathrm{kg}^{-1}$ ). A mixture of halothane (generally $2.5 \%$ ) in oxygen was used to induce anesthesia. Once anesthesia was achieved, a femoral vein on an anterior or a posterior limb was cannulated. A rectal thermometer was inserted at a sufficient depth to monitor core temperature, ECG (electrocardiogram) needle electrodes were positioned cross-axially, and EEG (electroencephalogram) screw electrodes were fixed in the skull above the frontal sinus. A tracheal cannula was inserted and anesthesia was continued with intravenous injections of sodium thiamylal (Surital) as required.

After placement of the animal in a stereotaxic frame, a small craniotomy was performed around Horsley-Clarke coordinates P4 L2. In the case of kittens at 2 and 3 weeks postnatal, bone structure in the skull is relatively fragile and suture borders between sections are especially weak. Special procedures are therefore required to secure the youngest kittens in position. For this purpose, small machine screws were placed into the skull bone at several locations and a low-heat dental impression compound (Mizzy Inc.) was used, which is pliable when heated and hardens upon cooling. We placed the heated material around the skull avoiding the area through which an electrode would be placed. The head of a bolt was submerged in the compound and after hardening, it was used to secure the head to the stereotaxic frame so that ear bars could be avoided. For kittens, we used the lamda suture rather than HorsleyClarke coordinates and performed the craniotomy around a region 4 $\mathrm{mm}$ anterior and $2 \mathrm{~mm}$ medial to the suture. Dura mater beneath the craniotomy was reflected and removed. A microelectrode was positioned at an angle of $10^{\circ}$ medial and $5^{\circ}$ anterior with the intention of traversing the medial bank of the postlateral gyrus as the electrode was lowered through striate cortex. A $3 \%$ agar gel at $38^{\circ} \mathrm{C}$ was placed around the electrode, and a sealed chamber was created with melted wax.

The animal was placed in front of a tangent screen and given a loading dose (around $10 \mathrm{mg} \cdot \mathrm{kg}^{-1}$ ) of gallamine triethiodide (Flaxedil) to cause paralysis so that eye movement was minimized. The cat was connected to a ventilator to provide artificial respiration with a mixture of $\mathrm{N}_{2} \mathrm{O}$ $(70 \%)$ and $\mathrm{O}_{2}(30 \%)$. Paralysis was maintained with Flaxedil infused at the rate of $10 \mathrm{mg} \cdot \mathrm{kg}^{-1} \cdot \mathrm{hr}^{-1 \mathrm{sl}}$. The Flaxedil is mixed with $5 \%$ dextrose or lactated Ringer's solution (1 and $3 \mathrm{ml} \cdot \mathrm{hr}^{-1 \mathrm{sl}}$ for kittens and adults, respectively). Pupils were dilated with atropine (1\%), and nictitating membranes were retracted with phenylephrine hydrochloride $(10 \%)$. Contact lenses with $4 \mathrm{~mm}$ artificial pupils were placed on each cornea. Temperature was monitored and maintained by use of a feedbackcontrolled heating pad unit at around $38^{\circ} \mathrm{C}$. Intratracheal pressure was monitored with a pressure gauge in the input tube from the respirator. ECG traces and end-tidal $\mathrm{CO}_{2}$ levels were also monitored. Expired $\mathrm{CO}_{2}$ was maintained at around $4.5 \%$ by adjusting tidal volume of the pump and occasionally by adding $\mathrm{CO}_{2}$ to the gas mixture. Light anesthesia was maintained by supplementation of the $\mathrm{N}_{2} \mathrm{O}$ with intravenous infusion of Surital $\left(1 \mathrm{mg} \cdot \mathrm{kg}^{-1} \cdot \mathrm{hr}^{-1}\right)$. Anesthesia was considered sufficient when pinches of a paw and tactile stimulation of an eyelid elicited no response and EEG patterns were synchronized.

Apparatus. A block diagram of our setup is illustrated in Figure 1. The cat faces a tangent screen upon which visual stimuli are backprojected via a modified overhead projector. Rectangular bright bars of variable dimensions may be presented manually via joy stick-controlled pen-motors. This system is used for initial exploration of receptive fields. Visual stimuli are also presented via CRT monitors placed so that left, right, or both eyes may be stimulated as shown in Figure 1. With these CRT monitors, large $\left(30^{\circ} \times 20^{\circ}\right)$ bright $\left(250 \mathrm{~cd} / \mathrm{m}^{2}\right)$ gratings with sinusoidal luminance distribution are presented via beam splitters to either eye or to both eyes together. Action potentials from individual neurons are recorded with electrolytically sharpened tungsten wires insulated with glass micropipettes (Levick, 1972). Potentials are amplified, displayed on an oscilloscope, and fed to an audio monitor. To isolate single-cell activity, a window discriminator is used from which spike data are sent to a computer for analysis.

Procedure. Once a cell is isolated, receptive fields are explored manually with bright bars of variable dimensions. We characterize the cell types, that is, simple or complex, based on the standard criteria of discrete $O N$ and OFF zones in the former case and mixed ON and OFF areas in the latter (Hubel and Wiesel, 1962). An additional criterion based on responses of cells to sinusoidal grating stimuli is also used to aid classification (see below). The ocular dominance of the cell is then noted according to the subjective 7 level scale of Hubel and Wiesel (1962) [cells excitable through only one eye are classed as group 1 (contralateral) or group 7 (ipsilateral), those activated equally by either eye are group 4 , and the remaining categories designate cells driven by either eye but more strongly by one]

After the initial subjective characterization of the cell is completed, the two CRT displays are positioned so that receptive fields are projected via the beam splitters onto the approximate centers of the screens. Quantitative tests are then made with drifting gratings in order to obtain optimal values of orientation, spatial, and temporal frequencies. To do this, we begin with a grating drifted at $2 \mathrm{~Hz}$ in front of one eye. This temporal frequency appears to activate all cells in the striate cortex (Movshon et al., 1978). Gratings are presented under computer control at several orientations (usually seven) clockwise and counterclockwise from the preferred orientation estimated by the initial tests. The same procedure is then used to determine optimal spatial frequency. In some cases, a temporal frequency set is also run but as noted above, temporal tuning for cortical cells is quite broad and $2 \mathrm{~Hz}$ is generally a nearmaximal value. All presentations in these and in subsequent tests are $4 \mathrm{sec}$ in duration, and multiple trials, generally 5-10, are used for each 
variable. All conditions in each sequence are randomly interleaved to reduce possible difficulties due to response variability.

A dichoptic stimulus set is then run with drifting gratings of optimal parameters. The initial phase of one grating (generally the right) is fixed while that of the other is shifted in $30^{\circ}$ steps so that 12 relative phase shifts cover $360^{\circ}$. In some cases, $45^{\circ}$ steps for eight relative phase values are also used. The phase-shifted gratings constitute changes in retinal disparity. Monocular tests and uniform fields with mean luminance equal to that of the grating patterns (blanks) are included in these runs to allow direct comparisons of monocular and binocular responses and to enable estimates of spontaneous activity, respectively.

Note that this procedure permits the determination of responses at relative retinal disparities. We are not able to measure absolute disparity responses. However, absolute disparity information is not critical because in this study, as in previous work, we are only interested in the degree of disparity selectivity (Freeman and Robson, 1982; Ohzawa and Freeman, 1986a). Since gratings are presented at the optimal orientation, disparity shifts are made along the dimension perpendicular to the preferred orientation. Perhaps the most serious technical problem with our procedure, as in other studies of a similar nature (e.g., Ferster, 1981; LeVay and Voigt, 1988), is the control of eye position. We use a reversible ophthalmoscope to project optic disks and approximate locations of areae centrales, but this does not yield precise estimates of fundus landmarks, especially in the case of young kittens. During the experiments, eye position is not monitored so that eye movements, which occasionally occur in paralyzed cats (Rodieck et al., 1967; Ferster, 1981), could occur during a dichoptic test. This would be seen as a shift in the PSTH (peristimulus time histogram) data.

There are two reasons why we believe that this is not a serious problem for the work described here. First, data from tests are monitored in real time so that apparent shifts in response phase may be detected during each sequence. This only occurs rarely and when it does, we stop the test and restart it again. The second reason why we believe that eye stability is not a problem here is that we have repeated a given sequence after a delay of around $15 \mathrm{~min}$ for a number of cells. In these cases, closely similar results have been obtained. In this context, it is important to note that our experiments only require relative phase. For this purpose, eye position must be stable only for the duration of each test (around $7 \mathrm{~min}$ ). Stability is not required across separate runs or between recordings from sequences of cells since the grating stimuli we use are large and periodic. This means that eye movements that occur between runs will shift the facilitation-suppression cycle (disparity tuning) along the phase axis, but not alter the basic pattern.

Histology. During the experiments, at the end of each penetration, a lesion was made by passing $10 \mu \mathrm{A}$ (DC current, electrode tip negative) for $10 \mathrm{sec}$ through the electrode tip. The electrode was then slowly withdrawn and several more lesions were made at regular intervals. At the end of each electrophysiological recording session, a lethal dose of sodium pentobarbital (Nembutal) was given to the kitten $(35 \mathrm{mg})$ or cat (75 mg) by intravenous injection. The animal was then perfused transcardially through the left ventricle with Ringer's solution followed by $10 \%$ formalin in saline. A large section of brain was removed in a block with a side parallel to the electrode tracks, and it was immersed in a $30 \%$ sucrose solution. The block was then sectioned at $40 \mu \mathrm{m}$ on a freezing microtome, and sections from the region of each electrode track were mounted and stained with thionin. A projection system on the microscope was used to provide sketches of lamina. Examination of these data showed that all recordings were from striate cortex (area 17) and cells were recorded from all lamina. Although sample size for each lamina is too small for definitive conclusions, there are no obvious laminar differences with respect to particular physiological function that we can identify.

\section{Results}

We studied a total of 24 cats. Of these, 13 were kittens of ages 2,3 , or 4 weeks postnatal and 11 were adults. Altogether, a total of 425 neurons were held for sufficient periods of time so that detailed study was possible and our full protocol could be completed. This number excludes cells with weak or erratic responses from which we were not able to obtain reliable data. Of this total, $51,121,78$, and 175 cells were recorded from 2, 3 , and 4 week postnatal kittens and from adults, respectively.

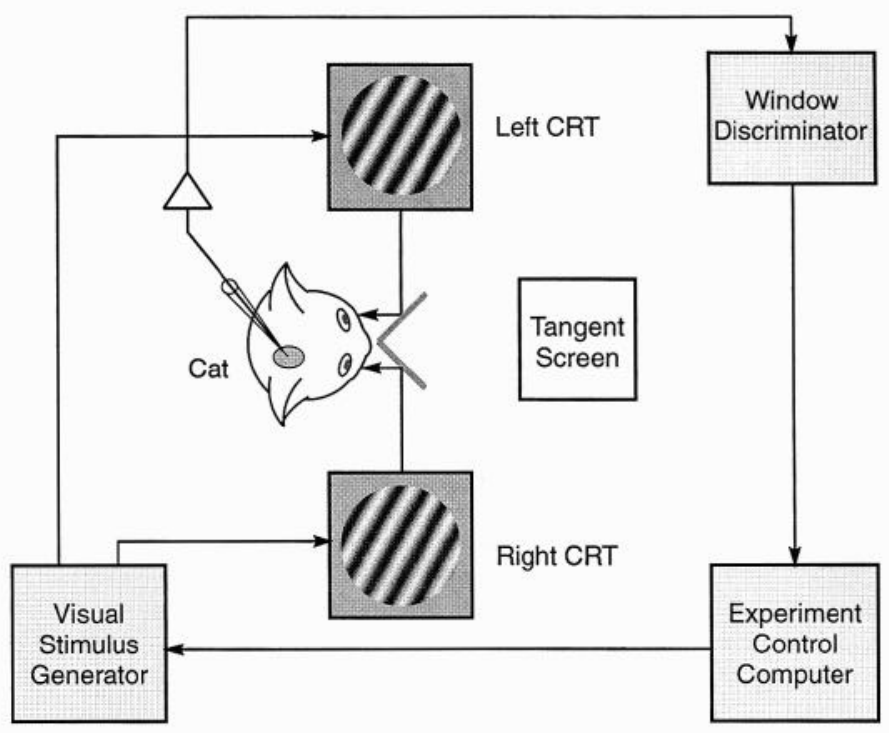

Figure 1. A schematic depiction of the apparatus is shown for electrophysiological recording from single cells in the visual cortex. Monoptic or dichoptic visual stimulation is achieved with this system. For details, see Materials and Methods.

\section{Adult cats}

As in numerous other studies, we are able to classify cells as simple or complex. For the former type, discrete ON and OFF regions are discerned with flashing bright bars presented at the optimal orientation. An additional criterion is used to classify simple and complex cells. Responses of simple cells to drifting sinusoidal gratings are highly modulated at the temporal frequency of the grating drift. Complex cells, on the other hand, show relatively unmodulated firing to the same stimuli. We therefore classify a cell as simple if the depth of response modulation (the ratio of the first harmonic amplitude in the PSTH at the temporal frequency of drift, to the DC component amplitude) is greater than 1.0. Otherwise, the cell is classified as complex (DeValois et al., 1982; Skottun et al., 1991).

Data from a representative simple cell are shown in Figure 2. In Figure 2, $A$ and $B$, results are given for monocular tests of left and right eyes to determine optimal orientation and spatial frequency. For this cell, peak values are $30^{\circ}$ and $15^{\circ}$ for left and right eyes, and 0.75 cycles/degree (c/degree) for both eyes, respectively. Note that responses are stronger for one eye (the right eye) and that preferred orientation differs by around $15^{\circ}$ as has been reported in other studies (e.g., Nelson et al., 1977). A small difference $\left(10-15^{\circ}\right)$ of preferred orientation for the two eyes is found for most cells and consistently in one direction. This most likely is the result of cyclo-rotation of the eyes in a paralyzed preparation (Blakemore et al., 1972; Bishop, 1978). It is also clear that tuning is quite narrow for both variables. Bandwidths for orientation and spatial frequency are $25^{\circ}$ and 1.7 octaves, respectively, and these values fall within the range of values found in previous studies (e.g., Henry et al., 1974; Watkins and Berkley, 1974; Heggelund and Albus, 1978).

Data from binocular tests are shown in Figure 2, $C$ and $D$. In Figure $2 C$, PSTH data are given for eight relative interocular phase (retinal disparity) values. Each disparity is separated by $45^{\circ}$ from the next value. In addition to the eight disparities, data are included for a null test in which no stimulus is presented, 

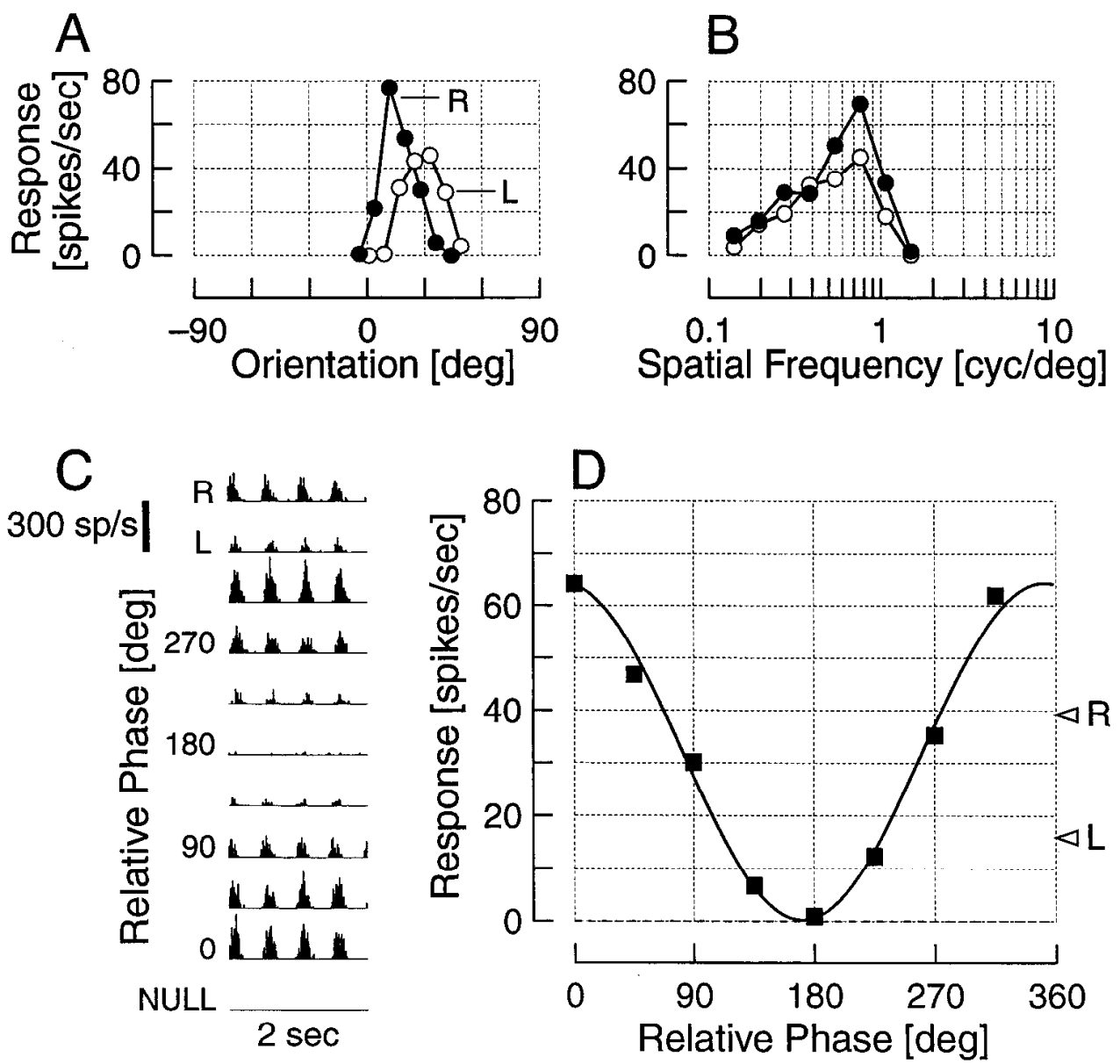

Figure 2. Responses of a simple cell from an adult cat are presented here. A, Orientation tuning curves are shown for left (open circles) and right (solid circles) eyes. Measurements are made using drifting sinusoidal gratings of $50 \%$ contrast, and temporal frequency of $2 \mathrm{~Hz}$. All other data presented in this article are also obtained with the same contrast and temporal frequency unless otherwise noted. For this run, a spatial frequency determined by a manual scarch procedurc is uscd (scc Matcrials and Methods). Zero degrees for orientation in this and all other figures represents horizontal. All stimulus conditions are presented in a randomly interleaved fashion. The amplitude of the first harmonic component of responses is used as the measure of response strength for simple cells. Preferred orientations for the left and right eyes are $30^{\circ}$ and $15^{\circ}$, respectively. $B$, Spatial frequency tuning curves are shown for the two eyes. The optimal spatial frequency is $0.75 \mathrm{c} /$ degree. $C$, PSTHs are shown in response to dichoptic presentation of drifting gratings. Relative phase between the two gratings is varied in $45^{\circ}$ steps. A blank stimulus condition (NULL) and monocular presentations $(R$ and $L)$ are interleaved in the stimulus set. $D$, Response strengths computed from data in $C$ are plotted against relative phase. A best-fitting (least-squares criterion) sinusoid for the dichoptic data is shown (solid curve) from which an index of the degree of binocular interaction (BII) is extracted. Monocular response levels are represented at the right margin $(R$ and $L)$. This neuron showed no spontaneous discharge.

that is, a blank screen with zero contrast and mean luminance equal to that of the gratings is presented. As is typical for simple cells, there is no spontaneous activity for this neuron. Finally, the PSTH data at the top of Figure $2 C$ show results from monocular tests run interleaved with those of the dichoptic sequence. All of these conditions were tested in a single interleaved run to reduce the effects of response variability over time. The data of Figure $2 C$ are harmonically analyzed (by discrete Fourier analysis) at the temporal frequency of the drifting grating, and the resulting first harmonic response amplitudes are plotted against relative phase of the gratings in Figure $2 D$. Also shown here, by arrowheads at the right margin, are the results of the interleaved monocular runs.

Since simple cells are characterized by linear spatial summation over their receptive fields, the expected result of phaseshifted dichoptic grating presentation is a periodic function with a period of $360^{\circ}$ as shown in Figure $2 D$. Note the exquisitely tuned response as relative phase is varied such that a smooth transition occurs from facilitation to suppression. In this case, the cell is totally suppressed at a relative phase of $180^{\circ}$ and maximally facilitated at $0^{\circ}$ or $360^{\circ}$. It should be noted that these phase values are relative since we are not able to measure absolute disparity. For example, the relative phase value of zero most likely does not represent a sinusoid aligned at corresponding points on the two retinas. All simple cells that can be driven by stimulation of either eye exhibit this phase-specific response. To determine the degree of binocular interaction, we obtain a binocular interaction index (BII) by fitting a cycle of a sinusoid to the binocular data in Figure $2 D$. This index is the ratio of the amplitude of the fitted sinusoid to the mean of all binocular responses (Ohzawa and Freeman, 1986a). This index is used to classify binocular interaction types (scc bclow).

Note for the data in Figure 2 that response amplitudes for the monocular tests done in conjunction with the dichoptic run are lower than those for orientation and spatial frequency sequences. This is a frequent finding, and it could be due to a relatively strong adaptation effect caused by dichoptic presentations. A full description of results of tests with simple cells 
A

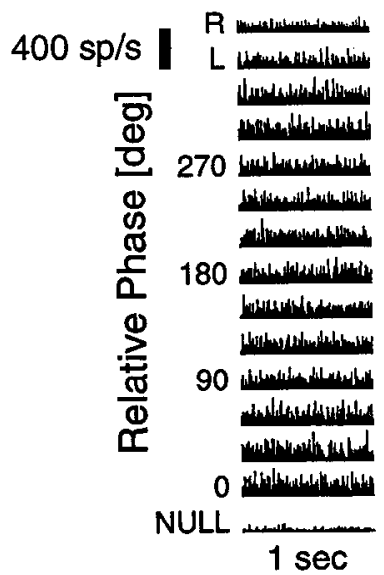

C

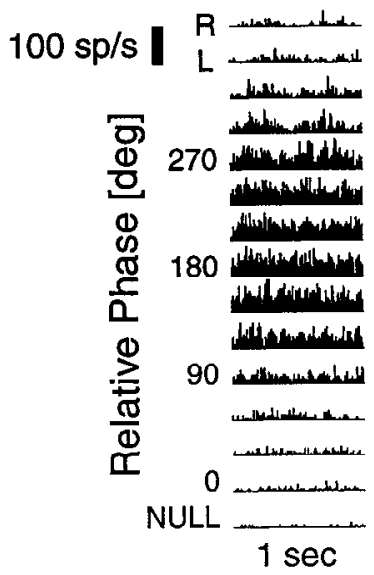

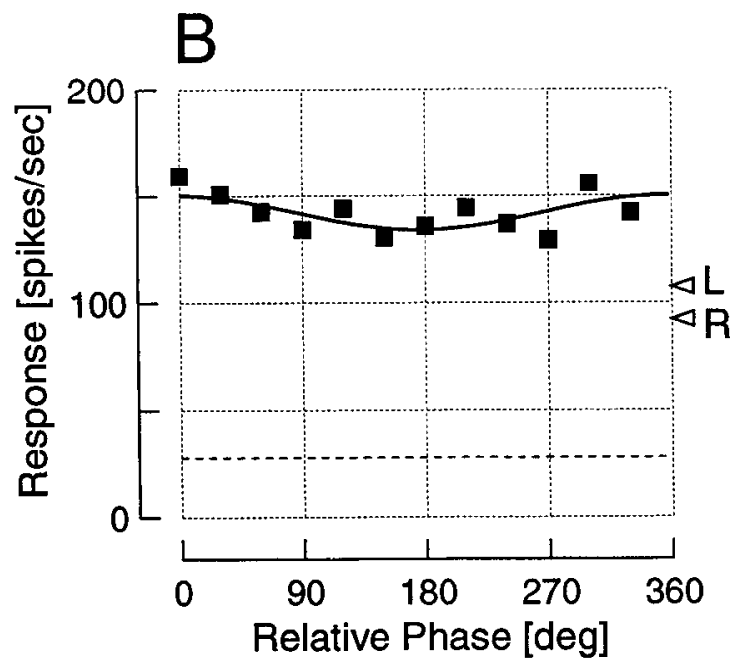

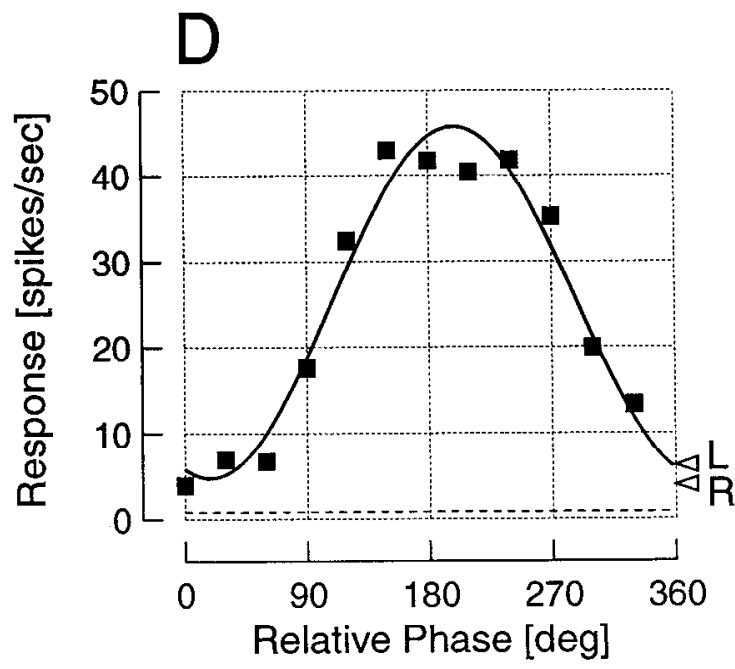

Figure 3. Responses of two complex cells from adult cats are shown. These complex cells display two main types of binocular interactions observed among complex cells; non-phase-specific and phase-specific types (see Results). For these tests, relative phase between dichoptically presented gratings are varied in $30^{\circ}$ steps. $A$ and $B$ show responses of a non-phasc-spccific complex cell in a format similar to that of Figure 2, $C$ and $D$. The preferred orientation and spatial frequency are $270^{\circ}$ and $0.4 \mathrm{c} /$ degree, respectively. $C$ and $D$ depict responses of another complex cell that exhibited a phase-specific binocular interaction. The preferred orientation and spatial frequency are $100^{\circ}$ and $1.2 \mathrm{c} /$ degree, respectively. The spontaneous discharge rates are shown in $B$ and $D$ by broken lines parallel to the horizontal axis. for dichoptic stimulation with phase-varying gratings for adults has been published previously (Ohzawa and Freeman, 1986a).

For complex cells, $\mathrm{ON}$ and $\mathrm{OFF}$ regions are mixed together within the receptive field and position of the stimulus within the receptive field is relatively unimportant. Therefore, relative phase shifts in the dichoptic mode should not change the discharge rate of the cell. For around $40 \%$ of complex cells, this expected finding is realized, and an example is shown in Figure 3, $A$ and $B$, which depicts PSTHs and phase tuning in the same format as Figure 2, $C$ and $D$, respectively. For this complex cell, responses are unmodulated and dichoptic stimulation results in a facilitatory response.

For another $40 \%$ of complex cells, dichoptic responses are phase specific and closely similar to those from simple cells. An example of this type of response is shown in Figure 3,C and $D$. In this case, dichoptic stimulation at the optimal relative phase elicited an enormous facilitation of the response that exceeded substantially the sum of the monocular responses. In previous work, we have shown that the phase-specific responses of these complex cells result from lincar summation of inputs from the two eyes at subunits that are organized similarly to simple cell receptive fields (Ohzawa and Freeman, 1986b). The remaining complex cells either were monocular or showed nonphase-specific suppression. In summary, since nearly all of sim- ple cells and about half of complex cells show phase-specific responses to dichoptic stimuli, the majority of cortical cells (around $75 \%$ ) in adult cats exhibit linear summation in binocular convergence.

\section{Kittens: 3 and 4 weeks postnatal}

At 3 and 4 weeks postnatal, we expected results to show clear differences from the properties of adult cells based on a previous study (Pettigrew, 1974), that is, a relatively large proportion of nonspecific responses and generally broad tuning functions for those cells that could be activated. This expectation was not fulfilled. In fact, we find that cortical cells in kittens at both 3 and 4 weeks postnatal are quite responsive and well tuned for all stimuli we presented including changes of binocular disparity. Furthermore, all binocular interaction types that are found in adult cats are also observed in these kittens. Since we do not find any substantial differences in terms of tuning properties between 3 and 4 weeks postnatal, we first present a brief summary of 4 week data, and more detailed results from 3 week kittens. This is because onc of the purposes of this study is to determine the earliest age at which one can observe disparity selective responses.

Four types of binocular responses from kittens at 4 weeks postnatal are shown in Figure 4. In this and in the following 
Figure 4. Responses of four cortical neurons from 4 week postnatal kittens are shown. Each panel represents results from different neurons. The format of each panel is the same as that of Figure $2 D$. Curves indicated by open and solid circles show results of identical measurements taken at different times (10-30 $\mathrm{min}$ apart) to estimate variability of responses over time. $A$, Data from a phase-specific simple cell are shown. The solid curve without symbols represents responses when the orientation of the grating presented to the left eye was made orthogonal to that for the right eye. $B$, Responses of a phasespecific complex cell are shown. $C$, Responses of a non-phase-specific complex cell are presented. $D$, Responses of a simple cell with non-phase-specific suppression are illustrated. Preferred orientations and optimal spatial frequencies of cells $A-D$ are, respectively, $357^{\circ}, 160^{\circ}, 0^{\circ}$, and $80^{\circ}$ and $0.6,0.6,0.8$, and $0.3 \mathrm{c} /$ degree.
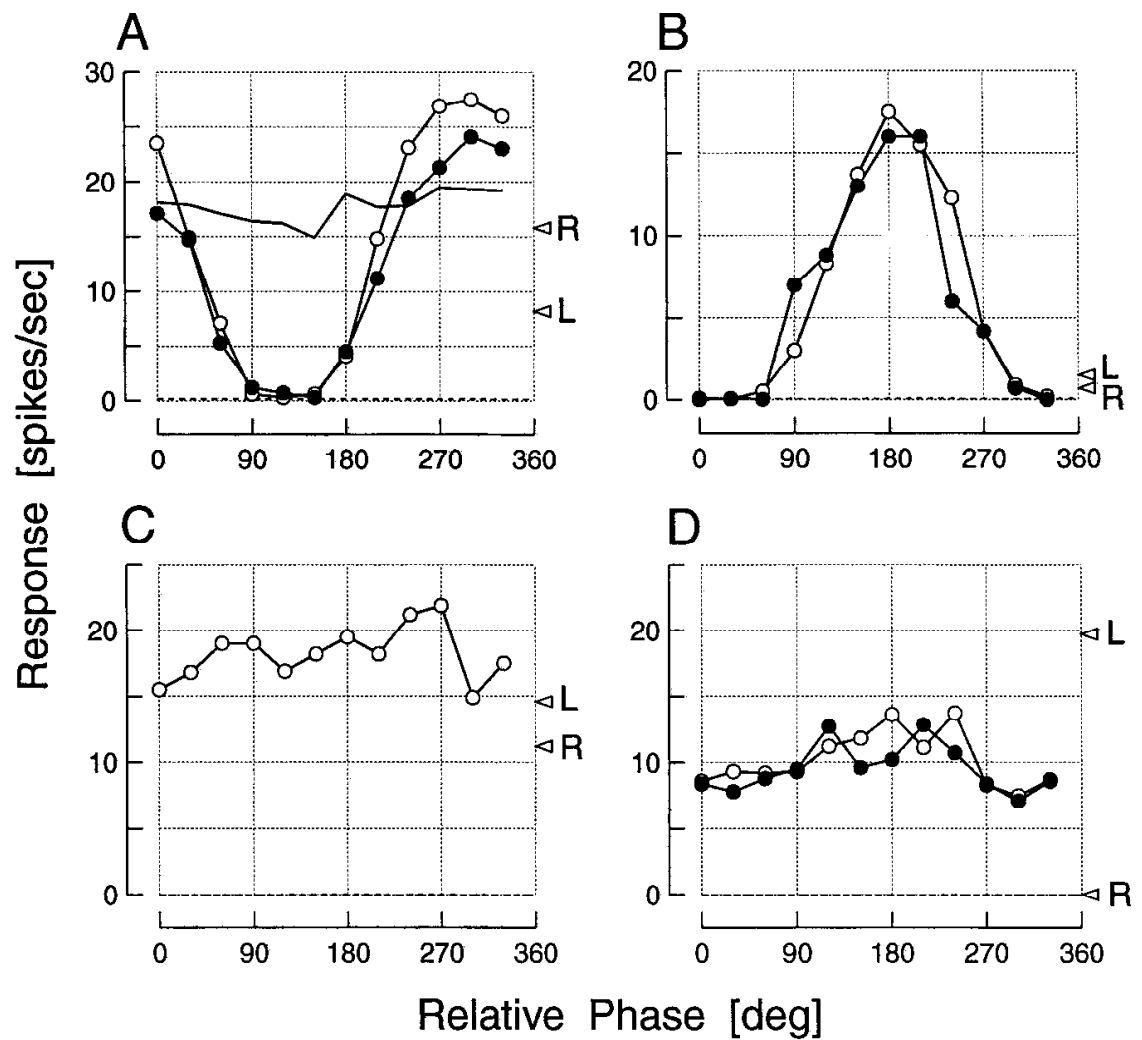

figures, we have connected the data points by line segments instead of showing a best-fit single cycle of a sinusoid. This is done to maintain clarity. For classifying the binocular response types, we have uscd a fitting procedure to obtain a binocular interaction index (BII) from each run. In Figure $4 A$, results from a dichoptic phase run for a phase-specific simple cell are shown. The basic features of the responses are indistinguishable from those of the adult simple cell shown in Figure 2. The response goes through a cycle of facilitation and complete suppression as the relative phase is varied over $360^{\circ}$. Results from an identical second run (solid circles) show a similar curve to the first one (open circles) except for a slight reduction in the response strength. This suggests that the method for obtaining relative disparity tuning functions is quite stable over time. We conducted similar repeat runs following delays of 10-30 min after the first sets for about $30 \%$ of the cells, and in each case, results were closely similar and quite consistent. The curve without symbols in Figure $4 A$ represents responses of the cell when the orientation of the left eye grating was perpendicular to that of the right eye (and optimal orientation). In this casc, no binocular interaction is observed. This was true for all cases in our previous study on adult cats (Ohzawa and Freeman, 1986a,b).

Figure $4 B$ shows results from a phase-specific complex cell. For this cell, the two repeated runs produced closely matched tuning curves. The maximum binocular response is substantially stronger than monocular response levels. The complex cell presented in Figure $4 C$ exhibited non-phase-specific facilitation. There is no relative-phase dependence in the binocular responses. The binocular response level, however, is somewhat stronger than either of the monocular response levels that are indicated by arrowheads at the right margin of the panel. The simple cell presented in Figure $4 D$ showed non-phase-specific suppression. Two repeated measurements show nearly identical response patterns. Cells exhibiting this type of suppression are nearly always monocular when examined one eye at a time. In this case, the cell could not be activated through the right eye at all, yet the simultaneous stimulation of this eye with the left eye produced markedly smaller responses than those elicited by stimulation of the left eye alone. These representative cells from 4 week postnatal kittens, presented in Figure 4, show that all four binocular interaction types found in adults are also present among cortical cells of 4 week kittens. Furthermore, all of the basic features of each response type are also similar to those of adults. A summary of the relative frequencies of each of these four types is presented below.

Results for a simple cell from the 3 week postnatal agc group are shown in Figure 5. Monocular tuning bandwidths are typical for orientation and spatial frequency $\left(47^{\circ}\right.$ and 1.5 octaves, respectively) for the right eye, which dominates the cell (ocular dominance is group 5). Responses are vigorous and regular for the right eye and weak but consistent for the left. In the dichoptic sequence (Fig. $5 C$ ), responses are clearly modulated at the temporal frequency of the drift rate. The results of harmonic analysis, shown in Figure $5 D$ for the first harmonic (open circles), indicate clear phase (disparity) specificity as observed in adults and 4 week kitten simple cells. Suppression is complete such that the cell is virtually turned off at relative phases from $120^{\circ}$ to $180^{\circ}$. A second curve (solid circles) represents data collected $20 \mathrm{~min}$ after the first dichoptic run was completed. Results for the second run are nearly superimposed on those for the first, indicating reliability and stability of measurements.

The BII value for this cell is 1.23 for the two tests, which indicates that it is highly tuned for relative phase. On the other hand, peak spatial frequency is relatively low $(0.25 \mathrm{c} /$ degree $)$, and therefore the effective disparity tuning is correspondingly broad if represented as spatial displacement (in arc minutes) 
A

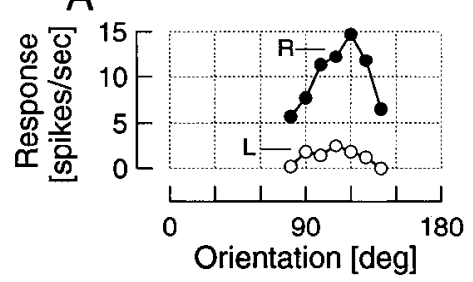

B

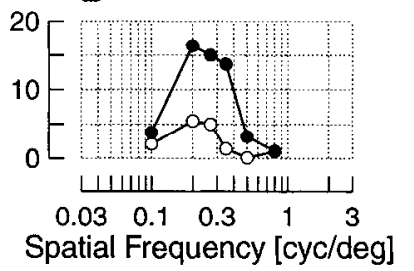

A

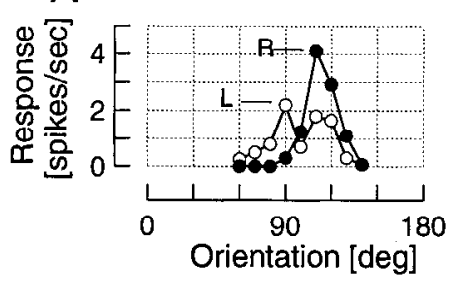

B

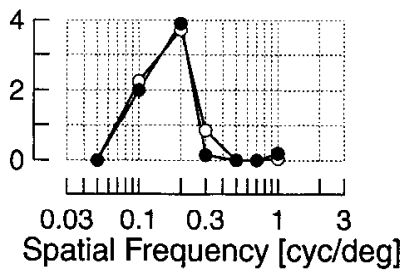

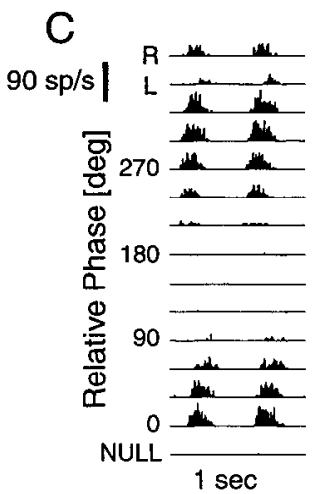

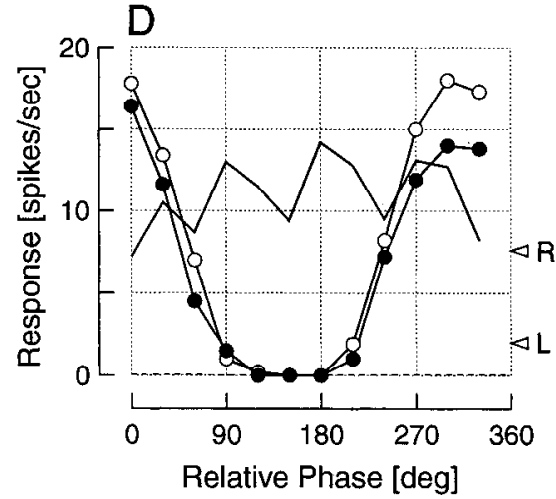

Figure 5. These results are for a phase-specific simple cell from a 3 week kitten. The format of the figure is identical to that of Figure 2 . In $C$ and $D$, relative phase between dichoptically presented gratings is varied in $30^{\circ}$ steps. $D$ shows the results of two repeated measurements taken $15 \mathrm{~min}$ apart (open and solid circles). The solid curve without symbols shows responses when the orientation of the left grating is made orthogonal to that of the right grating. The preferred orientations are $110^{\circ}$ and $120^{\circ}$ for left and right eyes, respectively. The optimal spatial frequency is $0.2 \mathrm{c} /$ degree.

rather than by phase. Although the optimal spatial frequency is within the standard range for adults (Movshon et al., 1978), mean peak spatial frequency clearly increases with age beyond 3 weeks postnatal (see below). Finally, note that peak response values for monocular tests interleaved in the dichoptic run are slightly lower than those for each eye tested alone (Fig. $5 A, B$ ). This may reflect an adaptation effect in the former case as noted above.

Another example of a response set from a kitten at 3 weeks is presented in Figure 6. In this case, the cell is a complex type and responses overall are relatively weak. The monocular data of Figure $6 B$ show well-tuned spatial frequency selectivity $(1.3$ octaves) with equal responses for left and right eyes. For the orientation tuning run (Fig. $6 \mathrm{~A}$ ), responses of the right eye are somewhat stronger and those for the left eye are irregular. What is striking about this cell's response pattern is that it is highly tuned for disparity. In the PSTH data (Fig. $6 \mathrm{C}$ ) for phases of $30^{\circ}-120^{\circ}$, the cell is completely silent. The spontaneous discharge is not particularly strong for a complex cell, but present nevertheless. The same result is shown graphically in Figure $6 \mathrm{D}$, which gives the average firing rate (DC component) response as a function of phase. The response changes sharply with phase (disparity) with a peak at $240^{\circ}$. The second curve here (solid circles) gives the result of a repeat test conducted $30 \mathrm{~min}$ after the first. Once again, results are quite similar, except for a small reduction in the responsiveness, and indicate that this method of determining the disparity tuning of cortical cells is consistent and reliable.

Results for a third cell from kittens at 3 weeks postnatal is shown in Figure 7 . In this case, the left eye is only slightly
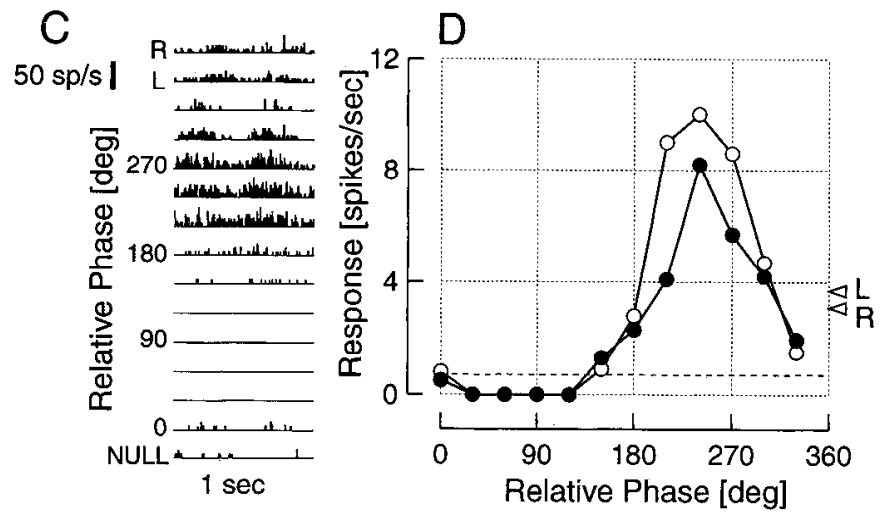

Figure 6. A complex cell from a 3 week postnatal kitten produces phase-specific responses. The format of this figure is identical to that of Figure 5 . The preferred orientation and optimal spatial frequency are $110^{\circ}$ and $0.2 \mathrm{c} /$ degree, respectively.

dominant, and orientation and spatial frequency tuning functions for both eyes are well defined (Fig. 7A,B). As is typical for around half of complex cells in adults, the PSTH data in Figure $7 C$ show an increase in overall average discharge rate that is relatively independent of phase. For this cell, null presentation yields nearly no spontaneous activity. Results of harmonic analysis at the zero harmonic (DC component) are shown in Figure $7 D$. Although response levels vary somewhat with phase, there
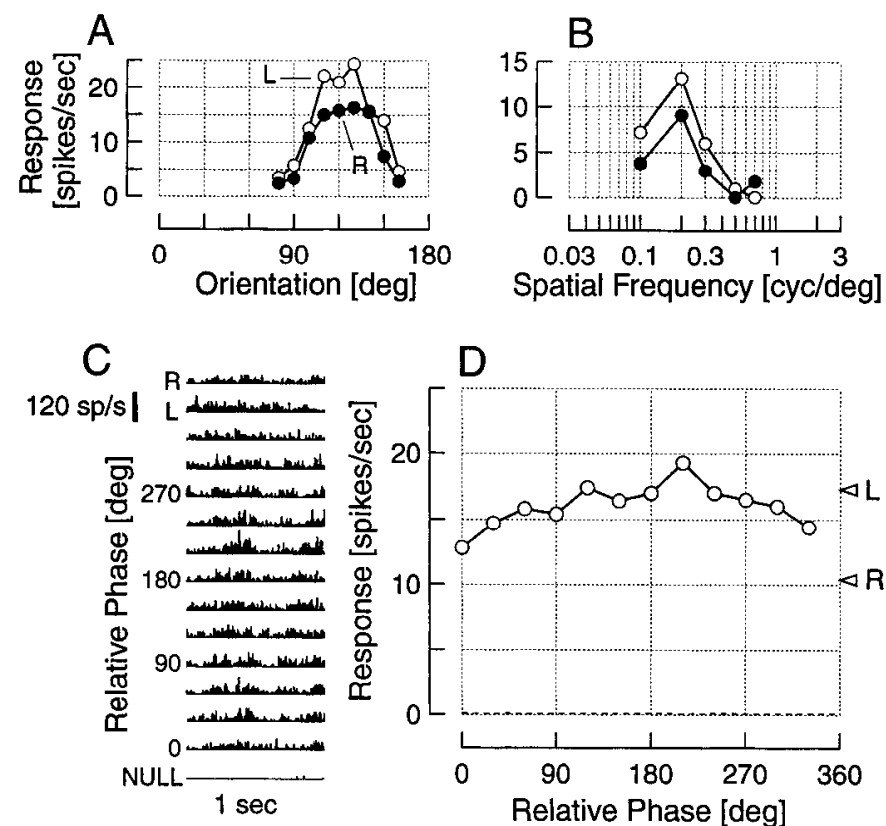

Figure 7. In this case, also for a complex cell from a 3 week kitten, binocular responses are non-phase-specific. The format of the figure is identical to that of Figure 5. The preferred orientation and optimal spatial frequency are $125^{\circ}$ and $0.2 \mathrm{c} /$ degree, respectively. 

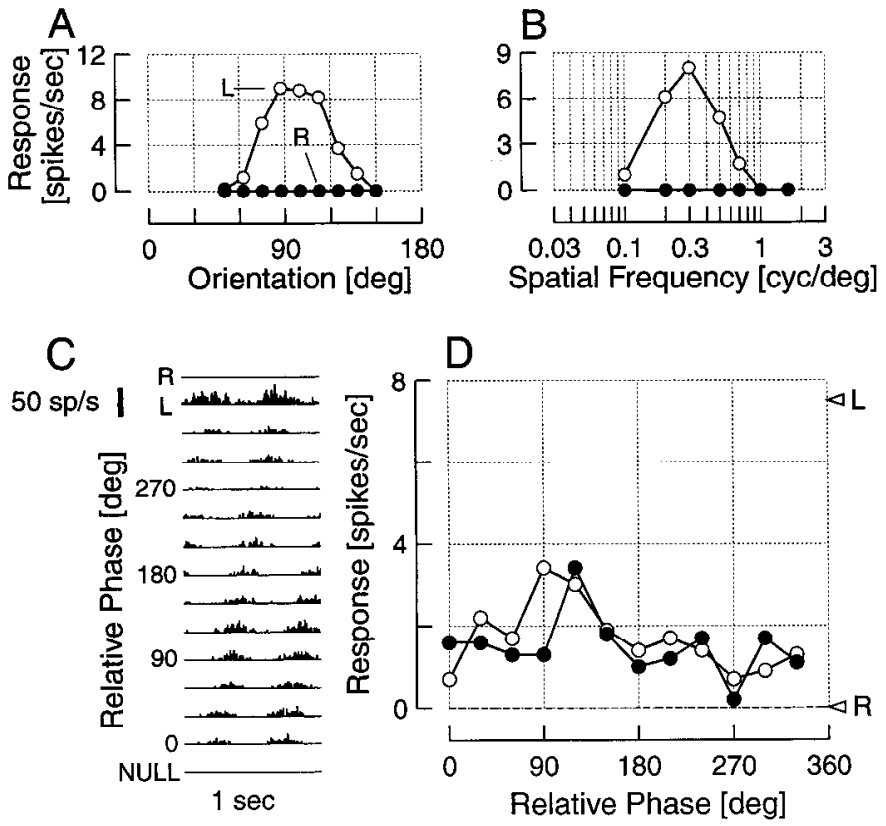

Figure 8. For this complex cell, also from a 3 week kitten, dichoptic responses are suppressed in a non-phase-specific manner. The format of the figure is identical to that of Figure 5 . The preferred orientation and optimal spatial frequency (for the left eye) are $100^{\circ}$ and $0.3 \mathrm{c} /$ degree, respectively.

is no clear disparity tuning. The BII is 0.12 , which is well below the criterion 0.3 for classification of phase specificity (Ohzawa and Freeman, 1986a). The discharge rate in response to dichoptic stimuli is comparable to that for monocular conditions. This type of non-phase-specific response is typical of complex cells in adult cats (Ohzawa and Freeman, 1986b).

Another type of binocular interaction from a 3 week kitten, relatively infrequently encountered, is given in Figure 8 . This is an example of non-phase-specific suppression. This is a complex cell, although substantial modulation is observed at the temporal frequency of the stimuli. The DC component of the responses is stronger for monocular stimulation (the left eye response of Fig. $8 C$, and the responses for the conditions of Fig. $8 A, B$ for which PSTHs are not shown). With dichoptic stimulation, where suppression of the response occurs, modulation of the response at the temporal frequency used is considerably enhanced, and this causes a reversal of the ratio of the first harmonic to the DC component. This type of borderline classification case is observed for cells that exhibit phase-specific binocular interaction as well as for the non-phase-specific suppression type.

Unlike the previous examples, the cell whose responses are shown in Figure 8 appears to be strictly monocular when tested one eye at a time (Fig. $8 A, B$ ). Clear responses are seen for the left eye, and tuning bandwidths for orientation and spatial frequency are typical of those found in adults $\left(53^{\circ}\right.$ and 1.9 octaves, respectively). The cell is completely silent for stimulation through the right eye, yet with dichoptic presentation, stimulation of the silent eye clearly has a suppressive effect. This effect is seen in the PSTH data of Figure $8 C$ for the dichoptic sequence. For the right eye, there is no response. However, for phase-varying stimulation, responses are clearly reduced compared to monocular levels. This is seen graphically after harmonic analysis (Fig. 8D) so that responses are suppressed across the full range of relative
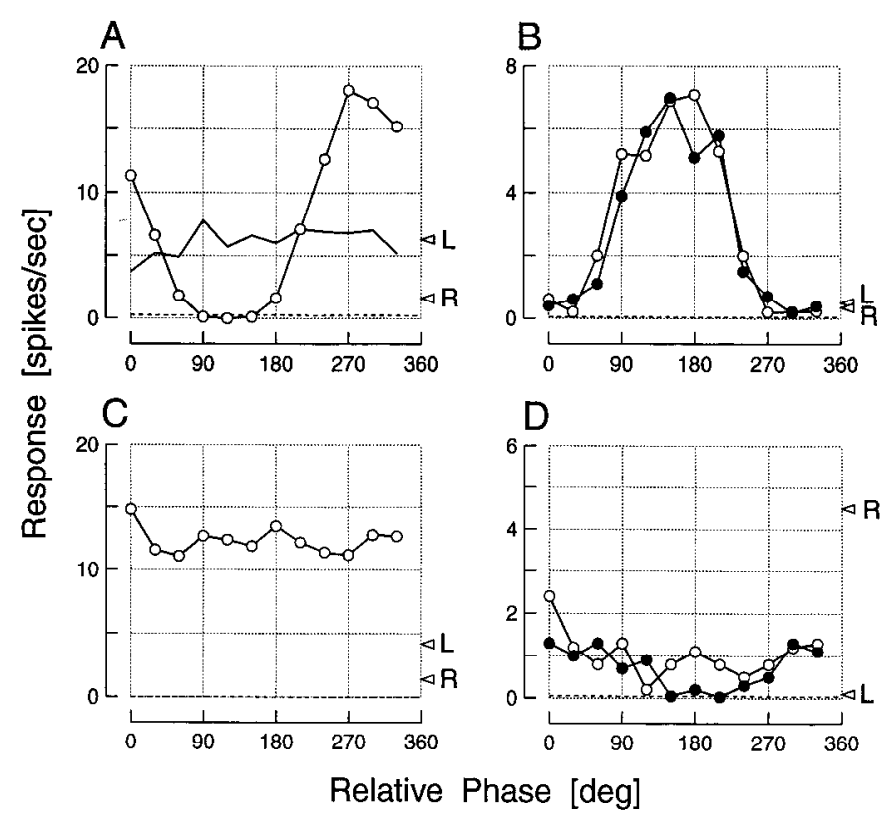

Figure 9. Responses of four additional cells from 3 week postnatal kittens are shown here. Results in each panel are from different cells. The format of each panel is the same as that of Figure $2 D . A$, Data from a phase-specific simple cell are shown. The solid curve without symbols denotes responses when the orientation of the grating for the right eye is orthogonal to that for the left eye. $B$, Responses are shown for a phasespecific complex cell. Results of two repeated measurements are presented (open and solid circles). C, Data from a complex cell that exhibited non-phase-specific facilitation are shown. $D$, In this case, a simple cell exhibited non-phase-specific suppression. Results of two repeated measurements are presented. Preferred orientation and optimal spatial frequency of cells $A-D$ are, respectively, $80^{\circ}, 200^{\circ}, 160^{\circ}$, and $120^{\circ}$ and 0.2 , $0.2,0.4$, and $0.2 \mathrm{c} /$ degree.

phases. Once again, a second complete dichoptic run was made (solid circles) 20 min after completion of the first and results are nearly superimposed. These results demonstrate clearly that an eye that is unresponsive when stimulated alone can be clearly influential and therefore functionally connected to the cell when tests are conducted in a dichoptic mode. We have observed this type of behavior previously in studies of both normal (Ohzawa and Freeman, 1986a,b) and visually deprived (Freeman and Ohzawa, 1988; Ohzawa and Freeman, 1988) cats.

Results from four additional cells from kittens at 3 weeks postnatal are shown in Figure 9. In Figure 9 $A$, data from a phasespecific simple cell are presented. As with the case presented in Figure 5, the phase-specific binocular interaction is lost when the orientation of the grating presented to one eye (right in this case) is made orthogonal to that for the other eye (which is the preferred orientation). Figure $9 B$ shows results from a phasespecific complex cell. Interleaved monocular tests elicit almost no response from the cell. However, binocular stimuli reliably produce highly facilitated responses. Nearly identical results from two repeated runs show the stability of cell responses and measurements. Figure $9 C$ represents results from a complex cell that exhibited non-phase-specific facilitation. Virtually no tuning for relative phase is observed. The BII is 0.02 . The binocular responses are much stronger than either of the monocular responses, indicating a high degree of binocular facilitation. Figure $9 D$ presents data from a simple cell that showed non-phasespecific suppression. Binocular responses are strongly suppressed from the monocular response level for the right eye. 

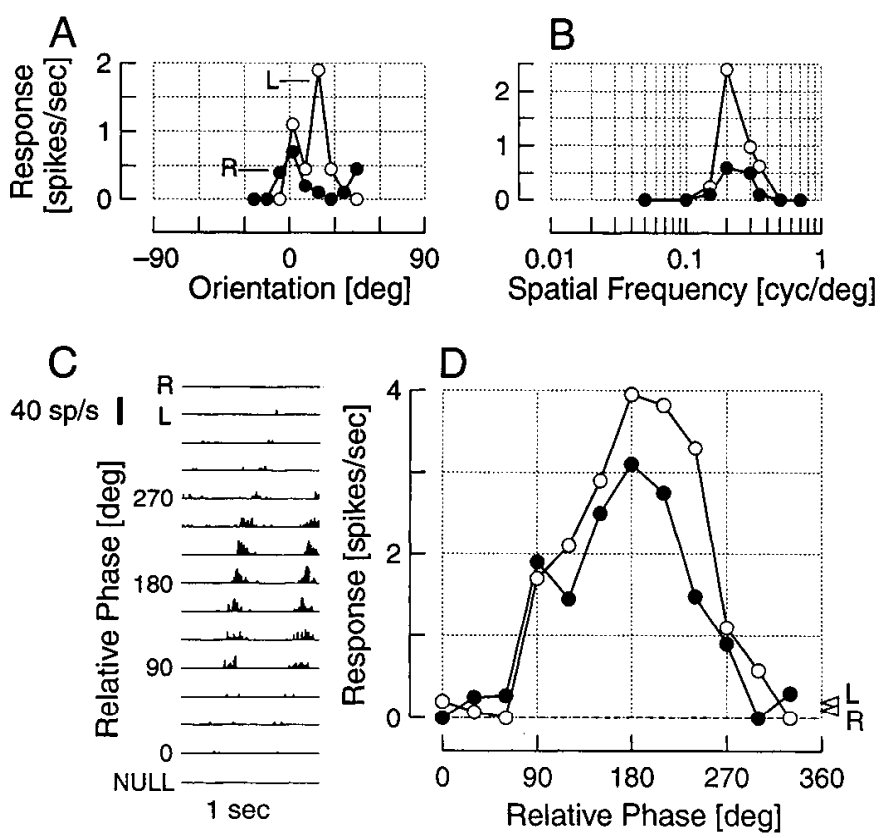

Figure 10. Data are presented here for a phase-specific simple cell from a 2 week postnatal kitten. The format of the figure is identical to that of Figure 2. The preferred orientations are $20^{\circ}$ and $5^{\circ}$ for the left and right eyes, respectively. The optimal spatial frequency is $0.2 \mathrm{c} /$ degree. $D$ shows results of two repeated measurements (open and solid circles).

The cell could not be driven through the left eye as is typical for this type of neuron.

Considered together, these results show that all three types of binocular interactions found in adults and 4 week kittens, phasespecific interaction, non-phase-specific facilitation, and nonphase-specific suppression, are also commonly found for cells of 3 week kittens. There is no qualitative difference in the basic nature of these interactions between adults and kittens of this age. A summary of the proportions of various interaction types is presented below.

\section{Kittens: 2 weeks postnatal}

At 2 weeks, it is difficult to record reliably from cells for relativcly long periods. Responses are also quite weak in general, even from cells for which consistent data may be obtained. In addition, many cells are unresponsive or erratic and when recorded, they appear to be more susceptible to adaptation and fatigue. These and other characteristics have been noted in previous work (see, e.g., Pettigrew, 1974; Blakemore and Van Sluyters, 1975; Fregnac and Imbert, 1978; Bonds, 1979; Albus and Wolf, 1984; Braastad and Heggelund, 1985). Nevertheless, we were able to record successfully from some cortical cells in kittens at 2 weeks. Results from a cell from a 2 week postnatal kitten are shown in Figure 10. The monocular characteristics are conventional except that response strength is quite low (Fig. $10 A, B)$. In the dichoptic mode, responses are clearly modulated and phase specific. The PSTH data (Fig. 10C) show that the monocular responses, which were weak initially, are now silent. Binocular responses are seen for phase values between $90^{\circ}$ and $270^{\circ}$. Results of harmonic analysis of the data, presented in Figure $10 D$ (first harmonic), show clear disparity tuning. A repeated dichoptic sequence, run 40 min after the first, results in a completely consistent disparity tuning profile (solid circles) with only a small reduction in responsiveness.

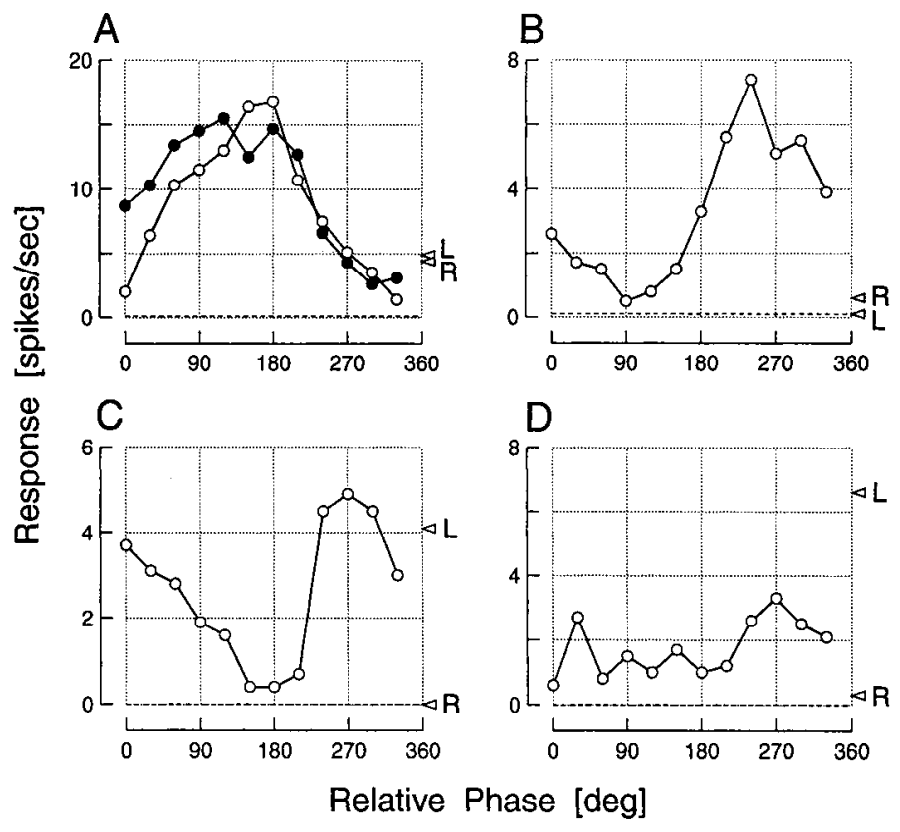

Figure 11. Responses are shown of four additional cells from 2 week postnatal kittens. Results in each panel are from different cells. The format of each panel is the same as that of Figure $2 D$. $A$, Data from a phase-specific simple cell are shown. Results of two repeated measurements are presented. $B$ and $C$, Results from two phase specific simple cells are presented. $D$, Responses from a simple cell that exhibited nonphase-specific suppression are shown here. Preferred orientations and optimal spatial frequencies of the cells $A-D$ are, respectively, $29^{\circ}, 200^{\circ}$, $200^{\circ}$, and $39^{\circ}$ and $0.2,0.1,0.2$, and 0.25 c/degree.

Additional examples of binocular responses of cells from 2 week postnatal kittens are given in Figure 11. Figure $11 A-C$ represents results from phase-specific simple cells. A repeated measurement in Figure $11 \mathrm{~A}$ again confirms reliability of the measurements and stability of the responses. A simple cell, presented in Figure $11 D$, exhibited non-phase-specific suppression where the binocular response level is around half of that for the left eye alone. These results show that even at 2 weeks postnatal, cells in the kitten's visual cortex are binocular and exhibit the same types of binocular interactions as those found in normal adult cats. We note, however, that responses are generally very weak and substantial numbers of cells cannot be studied reliably at this age. These factors are considered below (see Discussion).

\section{Summary of monocular characteristics}

Since we have conducted detailed monocular measurements of orientation and spatial frequency tuning properties of all cells we studied, data are available to show how these characteristics vary with age. The properties we have summarized are orientation bandwidth, spatial frequency bandwidth, optimal spatial frequency, and peak response as presented in Figure 12A-D, respectively. Sample sizes for kittens of 2, 3, and 4 weeks and for adults are $39,102,66$, and 106 , respectively. These sample sizes are slightly smaller than those for Figures 13 and 14 because of incomplete data for some monocular runs (e.g., some orientation tuning runs did not span a sufficiently large range, thereby missing the falloff to below half of the peak on one side). For each cell, the dominant eye was used to obtain the data, that is, the eye through which the greatest response was obtained for optimal stimuli.

Figure $12 A$ presents orientation tuning bandwidth, calculated 


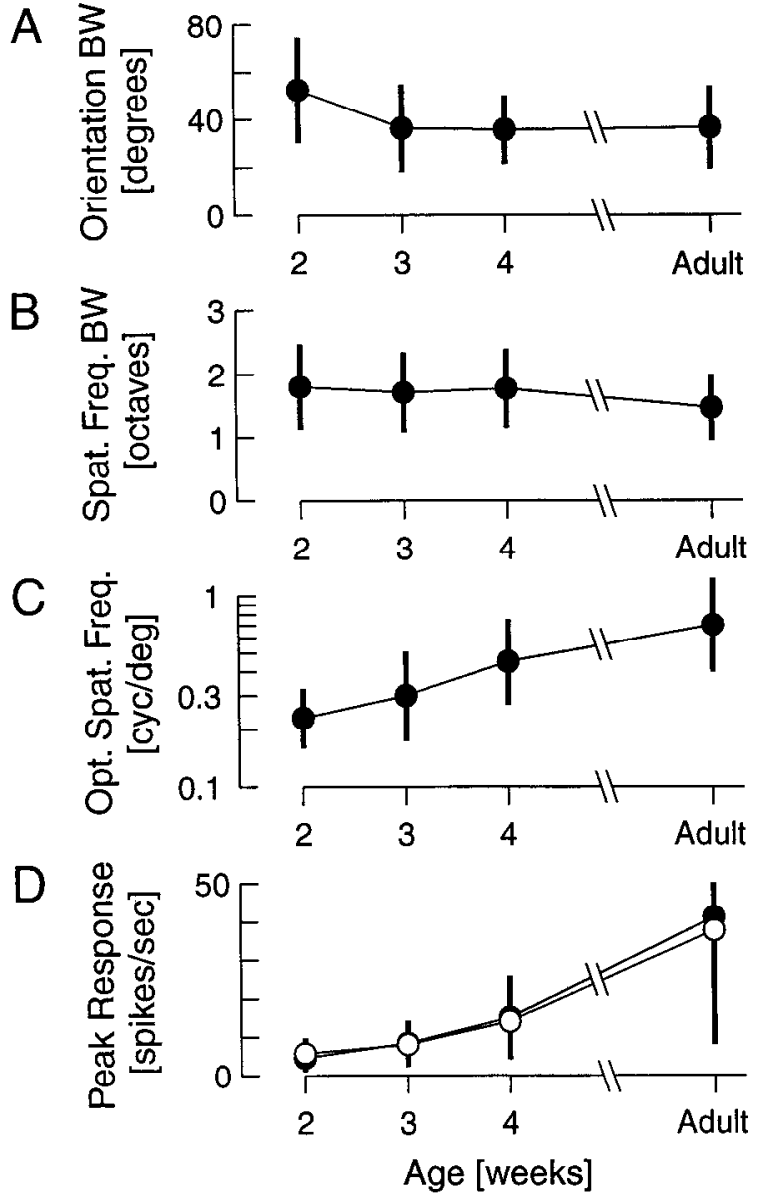

Figure 12. Development of monocular properties of cortical neurons is presented. Each data point depicts the mean of the values for all cells at each age group. Error bars in all panels show the SD of the mean. $A$, Development of the bandwidth for orientation tuning is given (full width at half of the peak response). $B$, Development of the bandwidth for spatial frequency tuning is shown (full width at half of the peak response in octaves). $C$, Development of optimal spatial frequencies of cells is shown. $D$, Development of peak firing rates of cells is shown for binocular (solid circles) and monocular (open circles) tests. The peak firing rate is the maximum DC or the first harmonic amplitude determined by harmonic analysis of PSTH data in response to presentation of drifting sinusoidal grating stimuli. The upward error bar for adults in this panel is clipped at 50, but is nearly the same length as the downward error bar. This is done to show changes of the means clearly.

as the full width of the tuning function at half the height of the curve, that is, at half the maximum response, at each age. The curve is flat from 3 weeks postnatal to adult ages, but it is somewhat broader at 2 weeks. Spread of the distribution is roughly comparable at all age groups. These results on bandwidth show that developmental changes are minimal for orientation tuning for the entire age range studied. Spatial frequency bandwidth (Fig. 12B), calculated as the width of the tuning curve in octaves at half the full amplitude of the response, is virtually flat across all ages, and spread of the distribution is also nearly constant. The mean bandwidths are just below 2 octaves for all ages.

Mean optimal spatial frequencies, shown for kittens of different ages and for adults, are presented on a log scale, since spatial frequency tuning curves possess, on average, constant octave bandwidths despite changes in the center frequency as shown in Figure $12 \mathrm{~B}$. This indicates geometric scaling with respect to spatial frequency. The means and the SDs are computed accordingly as geometrical means. As the data show, mean optimal spatial frequency increases monotonically through all kitten ages studied and from the oldest kitten to the adult. Spread of the distribution of optimal values is approximately constant at all ages. The fineness of disparity tuning depends on the preferred spatial frequency of the neuron. Therefore, the data on optimal grating spatial frequency at different ages are a factor that affects developmental changes in disparity sensitivity. This implication is considered in some detail in the Discussion.

Response strength of cortical neurons is known to be relatively weak in young kittens, and we examined how it changes with age. Figure $12 D$ shows the development of the peak response. Peak firing rates are obtained separately for monocular and binocular conditions. Maximum firing rates are used as determined by harmonic analyses of PSTH data, and the values do not represent instantaneous firing rates. Although peak responses are obtained separately for monocular and binocular conditions, the two show nearly identical changes with age. Of course, as we observe from phase tuning curves and monocular control levels, the maximum binocular response is almost always greater than monocular responses when they are interleaved in a single run. The similarity of the monocular and binocular peak responses in Figure $12 \mathrm{D}$ reflects a general tendency that the monocular peak firing rates in the first two monocular tests (orientation and spatial frequency tuning) are quite high, but are reduced substantially once interleaved into the binocular stimulus set. In any case, the peak response grows dramatically with age, and this change clearly continues well after 4 weeks postnatal.

Considered together, these data show that monocular tuning characteristics for cortical cells are established quite early developmentally. The implication is that the wiring that underlies this specificity is genetically established and does not require visual experience in the early stages.

\section{Summary of binocular characteristics}

The standard estimate of binocularity of a neuron is a judgement of the relative degree to which a given eye dominates a cortical cell. Ocular dominance is specified by a subjective scale, generally 1-7, first used by Hubel and Wiesel (1962), to indicate the degree to which a given eye dominates a neuron. However, the test is conducted monoptically and it does not provide information about how a cell responds when both eyes are activated simultaneously. To be fair, Hubel and Wiesel's original definition of the 7-scale ocular dominance classification contains provisions for taking into account inhibitory and subthreshold influences from the nondominant eye. In practice, however, these influences from the nondominant eye have been ignored or missed in almost all studies because they are not detectable with standard monoptic tests. For this reason, ocular dominance can only provide at best a rough measure of binocularity of a population of cortical neurons. Howcver, this classification system is so universal that we have noted the ocular dominance of each neuron that we studied. We base our subjective classification of ocular dominance on graphic plots of responses obtained in the first two runs for each cell, that is, orientation and spatial frequency tuning curves for left and right eyes (e.g., panels $A$ and $B$ of Figs. 2, 5-7, 8, and 10). Ocular dominance distributions for the kittens are similar among themselves and similar to those of earlier studies from our laboratory as well as those 

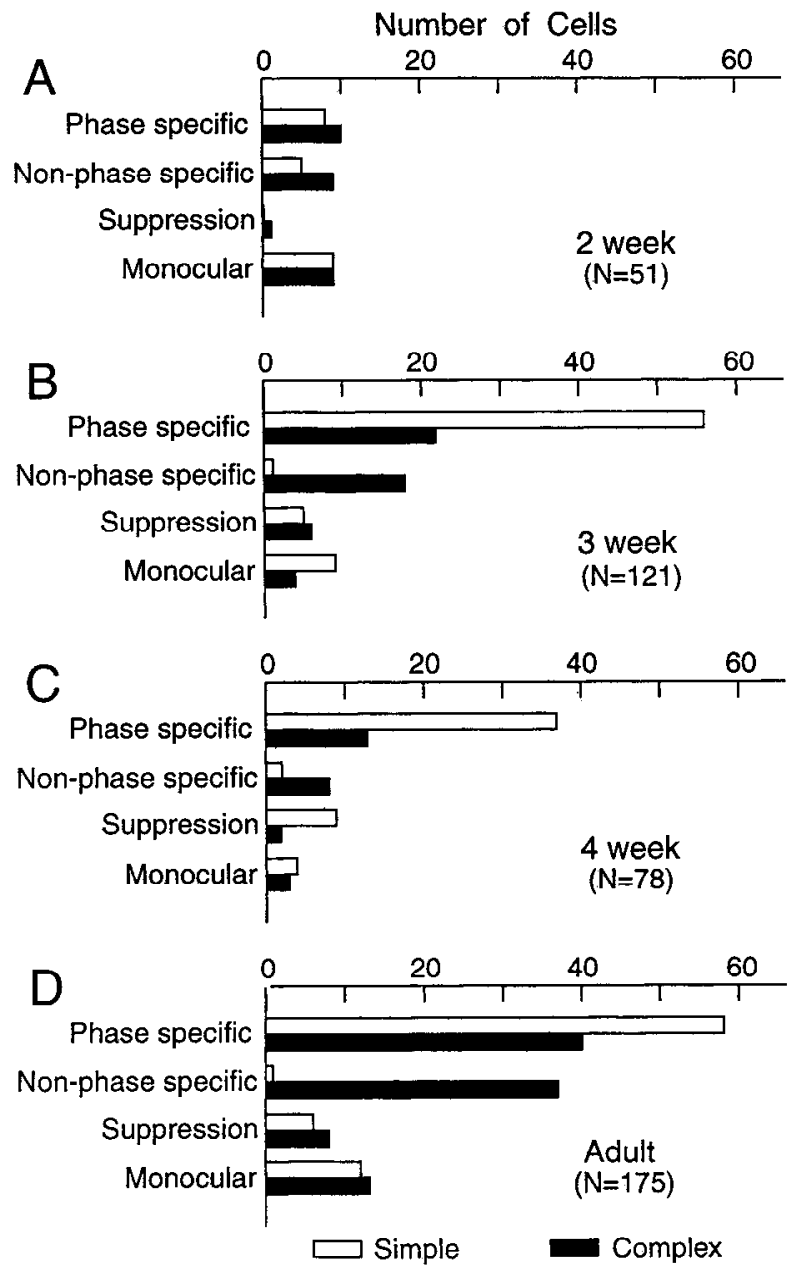

Figure 13. Cells are classified into four groups according to the type of their binocular interaction. The classifications are made separately for simple and complex cells for each age group. See Results for details of each classification.

of others. Specifically, all ocular dominance histograms peak around the center and show that a large majority of cells are driven by either eye. This obtains for kittens at all ages studied and for adults.

A better method to characterize the binocular properties of cortical neurons is to study them with dichoptic stimuli. Inputs from the two eyes may interact extensively, as shown in a number of studies (e.g., Barlow et al., 1967; Bishop et al., 1971; Ferster, 1981; LeVay and Voigt, 1988). We have studied these binocular interactions developmentally with robust stimuli spanning large regions of the visual fields. A summary of the results for the four age groups we have studied is as follows.

Types of binocular interaction as determined by dichoptic presentation of phase-varying gratings are shown in Figure 13. For 3 and 4 week postnatal kittens and adults, the majority of binocularly excitable simple cells show phase-specific binocular interaction. In addition, binocularly excitable complex cells, which comprise the majority, are nearly equally divided into phase-specific and non-phase-specific types. The remaining categories, non-phase-specific suppression and monocular, both have small and comparable proportions in 3 and 4 week kittens and adults. Therefore, the results indicate that binocular interaction characteristics of cortical cells from kittens of postnatal weeks 3 and 4 are quite similar to each other and to those from

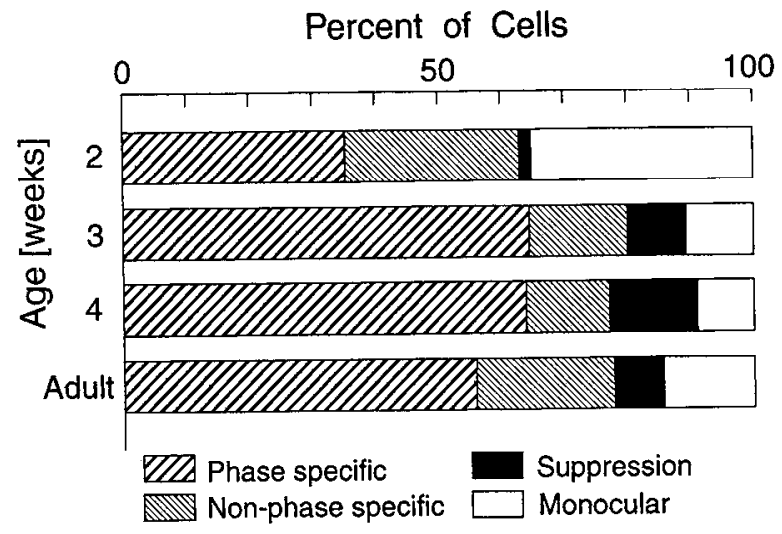

Figure 14. The change of relative proportions of the four major categories of cells, as a function of age, are presented here. The data of Figure 13 are summarized here to make changes with age clearer.

adults. Sample size is relatively small for the 2 week group, but patterns are generally similar to those for the other ages. There are more phase-specific complex cells than simple for the 2 week group, and this is clearly the reverse of that for the other ages. There are also relatively more monocular cells for the 2 week group, and this is shown more distinctly in Figure 14.

A further summary of these data is given in Figure 14. For each age group, four categories are shown. First, proportions are indicated for cells that showed phase-specific binocular interactions (coarsely hatched areas). This category includes those cells that appeared monocular when each eye was stimulated alone, but exhibited clear phase-specific interaction when binocularly stimulated. Proportions in this category for 2,3 , and 4 week postnatal kittens and for adults are $35 \%, 65 \%, 64 \%$, and $56 \%$, respectively. Clearly, the proportions in this category remain relatively constant with age from 3 weeks postnatal. A second category (finely hatched areas) is cells that are clearly activated through each eye alone but do not exhibit tuning for relative phase. No substantial change is observed for the proportions of cells of this type at all ages. A third category (solid areas) is cells that appear to be monocular when only one eye is tested at a time. However, dichoptic stimulation shows clear binocular function, which in this case is one of inhibition. When both eyes are stimulated simultaneously, the cell's response is suppressed to below that for monoptic stimulation alone. The important point here is that the correct assessment of the physiological status of this cell is not obtained by monoptic stimulation. Only dichoptic stimulation reveals the functional input from the eye that is silent when it is stimulated alone. Therefore, these three categories together represent cells that are binocular in the widest sense, such that cells maintain some functional connections (excitatory or inhibitory or both) from the two eyes. The proportions of binocular cells are $65 \%, 89 \%, 91 \%$, and $86 \%$, respectively, in kittens at 2,3 , and 4 weeks postnatal and in adults. Finally, a fourth category is included in Figure 14 that indicates monocular cells (open areas). These neurons can only be activated through one eye and did not show any binocular interaction. These are cells for which we could not detect any evidence of binocularity, that is, no excitatory or inhibitory input from one eye. In this case, dichoptic stimulation gives results that are identical to those from monoptic tests. Once again, data for 3 and 4 week kittens and adults are closely similar to each other. A substantially higher proportion of monocular cells is found for kittens at 2 weeks. The proportions for 2,3 , 


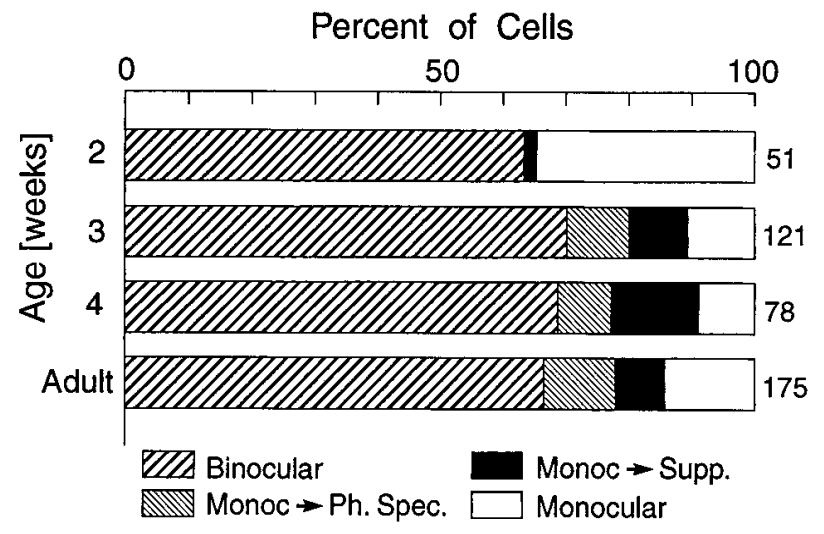

Figure 15. Proportions of monocular and binocular neurons, as estimated by monoptic tests and dichoptic measurements, are shown for each of the age groups we have studied. The areas with coarse hatching represent neurons that are determined as binocular by alternate tests of each eye (ocular dominance groups 2-6). The areas with fine hatching represent apparently monocular cells that show phase-specific binocular interactions. The solid areas indicate the proportions of cells that appeared monocular but showed non-phase-specific suppression. The open areas represent the proportions of true monocular cells.

and 4 week kittens and for adults, are $35 \%, 11 \%, 9 \%$, and $14 \%$, respectively.

Finally, it is of interest to compare estimates of the degrees of binocularity of cortical cells using conventional monoptic tests with those obtained from dichoptic presentations. Figure 15 presents a summary of the "binocularity" of the sample of cells we studied. As a routine procedure, we determine the ocular dominance of each cell by visual inspection of tuning curves for spatial frequency and orientation. During these tests, stimuli are presented monoptically by interleaving left and right eye stimuli in a single run. The proportion of cells that have ocular dominance values $2-6$ is shown in Figure 15 for each age group as binocular (area with coarse hatching). Around $63-70 \%$ of the cells in all age groups appear to be binocular by this subjective determination. The rest of the cells appear to be monocular based on these monoptic tests. However, a substantial fraction of these apparently monocular neurons show clear binocular interactions. Except for the 2 week kittens, about a third of the apparently monocular neurons exhibit phase-specific binocular interactions (shown by finely hatched areas). Roughly another third of apparent monocular cells for 3 and 4 week kittens and adults show non-phase-specific suppression (shown by the solid areas). Together, these two groups of apparently monocular cells are in fact clearly binocular, and they represent approximately $20 \%$ of all cells at 3 weeks postnatal and after. There are apparently many more truly monocular cells in the case of kittens at 2 weeks. These results show clearly that binocular inputs to a substantial number of cells are missed if only monoptic tests are used. Therefore, the study of binocular function may be seriously compromised by the exclusive use of monoptic visual tests.

\section{Discussion}

In this study, we have determined monocular and binocular response characteristics of cortical cells in kittens at three different ages and in adult cats. Our aim was to provide data on developmental changes with an emphasis on binocular vision.

\section{General developmental factors}

In previous work, attempts have been made to estimate proportions of cells that are responsive and stimulus specific in kittens at different ages. Since optical quality does not appear to limit visual function (Bonds and Freeman, 1978), developmental changes occur primarily as a result of alterations in neural organization. Nevertheless, recording from an intact kitten at postnatal 1 or 2 weeks is extremely difficult. Recordings from peripheral pathways (retina and LGN) show that reliable responses occur during postnatal week 3 (e.g., Rusoff and Dubin, 1977; Daniels et al., 1978). Recently, an isolated retina-eyecup preparation has been used to study retinal ganglion cells in very young kittens. Results show that by postnatal day 9 , all ganglion cells are visually responsive (Tootle, 1991). Anatomical techniques, including the use of neuronal tracers and intracellular staining, have also been used. It has been shown, for example, that horizontal connections in the striate cortex of kittens emerge early but are refined considerably up to around the sixth postnatal week when patterns become adultlike (Callaway and Katz, 1990).

The question of proportions of responsive cells at different ages is difficult to assess adequately. To do this, one must advance an electrode slowly and methodically so as to isolate every cell possible along a track. A cell is unresponsive if it is not active during visual stimulation, but it must have sufficient spontaneous activity to allow its identification. While this may occur in the retina or LGN, cells in the visual cortex are generally silent or have low spontaneous activity, so it is not obvious how to specify proportions of visually active cells. If every other cell along an electrode track were silent, it would not be possible to distinguish this condition from one in which every cell was active. One could easily reach the fallacious conclusion that all cells were active in either condition. In our present study, we did not attempt to assess systematically the proportions of visually responsive cells in young kittens at different ages. However, at 3 weeks postnatal or older, nearly all cells we recorded were visually responsive and stimulus specific for orientation and spatial frequency. With the proviso mentioned above, that we may have failed to note some cells that were not visually activated, these results are consistent with those of previous studies (Albus and Wolf, 1984; Braastad and Heggelund, 1985). Considered together, these findings indicate that the spatial organization of cortical receptive fields is innate. Of coursc, therc could be some cells for which this does not apply, and their developmental specificity may rely on input from other neurons that are innately specified and act as precursors.

In previous work on developmental changes in the visual cortex of kittens, differences have been found with respect to cell type and cortical lamina (Albus and Wolf, 1984). In particular, simple cells are thought to emerge before complex cells. Complex cells were not found during the second postnatal week and were scarce during week 3 . This has been attributed to a lack of functional polysynaptic inputs (Albus and Wolf, 1984). Our experiments did not include kittens at ages younger than 2 weeks postnatal, and most of our data were obtained from animals of 3 weeks or older. We find no evidence of consistent differences in proportions of simple and complex cells at different ages. In our samples, simple cells comprised $43 \%, 59 \%$, $67 \%$, and $44 \%$ in kittens at 2,3 , and 4 weeks postnatal and in adults, respectively. Nearly all other cells were of a complex type, although there were some at the youngest ages for which 
categorization was somewhat difficult. Our finding that proportions of simple and complex cells remain constant during early development is consistent with that of Braastad and Heggelund (1985), who also found no evidence of differential emergence of these cell types.

Minimal attention has been paid in previous investigations to the possibility of laminar differences in developmental processes. However, Albus and Wolf(1984) report differences based on laminar analysis. Specifically, cells in layers 4 and 6 of areas 17 and 18 exhibit clear response patterns in the youngest kittens while those in layers 2,3 , and 5 are generally not visually responsive until the fourth postnatal week (Albus and Wolf, 1984). The implication is that input layers from the LGN are mature relatively early in development. On the other hand, Tsumoto and Suda (1982) report that maturation of functional properties of cortical cells begins in layer 5. According to their study, developmental maturation occurs considerably later in layers 2,3 , and the lower half of layer 6 .

This kind of laminar analysis requires large sample sizes in order to provide comparable numbers for each layer. Since our study requires extensive study of each neuron, we do not have sufficient sample sizes for realistic laminar comparisons. This is especially problematic for our sample of kittens at 2 weeks postnatal. However, our data from 3 week kittens and beyond suggest no developmental laminar differences. Our samples include cells from layers with mainly intracortical connections (2, 3 , and 5), and there are no obvious differences with age.

\section{Development of monocular properties}

For cells from which we recorded for periods sufficient to obtain reliable data, results show that monocular tuning properties for orientation and spatial frequency are nearly constant across all age groups. The exception is that orientation bandwidth is broader at 2 weeks, but spread is rather large and overlaps considerably with that for other age groups. In any case, the data are consistent with those of previous quantitative studies of orientation selectivity (e.g., Sherk and Stryker, 1976). Although these monocular tuning characteristics are generally constant with age, optimal spatial frequency values increase progressively from 2 weeks postnatal into adulthood. The rate of increase of optimal spatial frequency is 0.6 octave/week from postnatal week 2 to 4 . This is comparable with that reported previously (Derrington and Fuchs, 1981, their Fig. 4). As noted above (see Results), this change in optimal spatial frequency, together with other factors, contributes to the increase in the fineness of disparity selectivity with age.

\section{Development of binocular properties}

In general, binocular response characteristics are present in kittens at the youngest age we examined (postnatal 2 weeks). Furthermore, proportions of binocular cells and types and frequencies of binocular interactions are nearly identical from 3 weeks postnatal into adulthood. Even at 2 weeks, most cells exhibit responses to stimulation of either eye. Obviously, these results mean that binocular connections are formed and maintained in a precise arrangement from a very early stage in development. It is interesting to note that this occurs in spite of an apparent gross visual misalignment of the eyes of young kittens (Sherman, 1972). We have shown previously that this apparent misalignment applies to the pupillary axes but not to the visual axes, which appear to be constant from postnatal day 14 to adulthood (Olson and Freeman, 1978).
Since binocular interaction involves both excitatory and inhibitory processes, it is of interest to know if these two types of connections develop in a similar sequence. In one study, excitatory responses are reported to develop first (Pettigrew, 1974). However, a sccond report suggests that both binocular facilitation and binocular inhibition are demonstrable in kittens at 2 weeks postnatal, although no data are given (Albus and Wolf, 1984). Our results show clearly that both inhibitory and excitatory processes are active during binocular stimulation in kittens at the youngest age, that is, 2 weeks. This is because inhibition is needed to reduce binocular response levels below those for monocular activation in phase-specific binocular interaction experiments. Furthermore, the types of binocular interaction are relatively constant at all ages studied from the youngest kittens to the adults. Proportions of phase-specific cells in kittens at postnatal weeks 2,3 , and 4 and in adults are $35 \%, 65 \%, 64 \%$, and $56 \%$, respectively. Relative proportions of suppressive types are $2 \%, 9 \%, 11 \%$, and $8 \%$, respectively. Considered together, these results show that the neural organization of binocular vision is developed and functional at around the earliest age at which it can be effectively measured.

In spite of the early emergence of binocular vision in kittens, there are clear changes in other visually related functions with age. For example, neurotransmitter phenotypes develop relatively late in postnatal maturation (Fosse et al., 1989). The most prominent physiological difference that we have noted is between weeks 2 and 3. During this period, there is a substantial increase in proportions of binocular cells. General responsiveness of cells also changes dramatically, and quantitative experiments become much easier for 3 week kittens compared with 2 weeks postnatal. One possible explanation for this change is that the effective threshold for driving cortical cells is relatively high until around 3 weeks postnatal. In this case, it might be possible to lower the threshold by manipulation of the local environment of the cells from which we record by use of an excitatory neurochemical agent. We attempted to do this with three kittens at postnatal 2 weeks by use of a microiontophoretic procedure in which a three-barreled glass micropipette electrode was used. One barrel contained an electrolytically sharpened tungsten wire, a second barrel was filled with DL-homocysteate (DLH), and the third contained a $0.9 \% \mathrm{NaCl}$ solution used to balance current during iontophoresis of DLH. This procedure has been used in previous work and details are given in other reports (e.g., Blakemore et al., 1982; Ramoa et al., 1987). The experiments we did with DLH were not successful. It was not possible to increase levels of activity of cortical cells in the 2 week postnatal kittens. In fact, we had the impression that neural activity was actually reduced following some ejections. It is possible that a kitten's cortex at 2 weeks is not amenable to this kind of technique, which has many potential problems (Hicks, 1984).

Finally, results on the physiological development of binocular vision may be compared with those from a morphological view. Specifically, development of ocular dominance columns in layer 4 of the cat's visual cortex has been examined by use of autoradiography of transneurally transported proline (LeVay et al., 1978). There were periodic grain density variations at 3 weeks postnatal and an adult pattern by around 6 weeks. Physiologically, recordings in layer 4 showed that most cells were nearly equally responsive to cither cyc prior to 2 weeks of age. At 2 weeks, radioactive label formed a continuous band in layer 4 , but spillover problems complicate the interpretation of these 


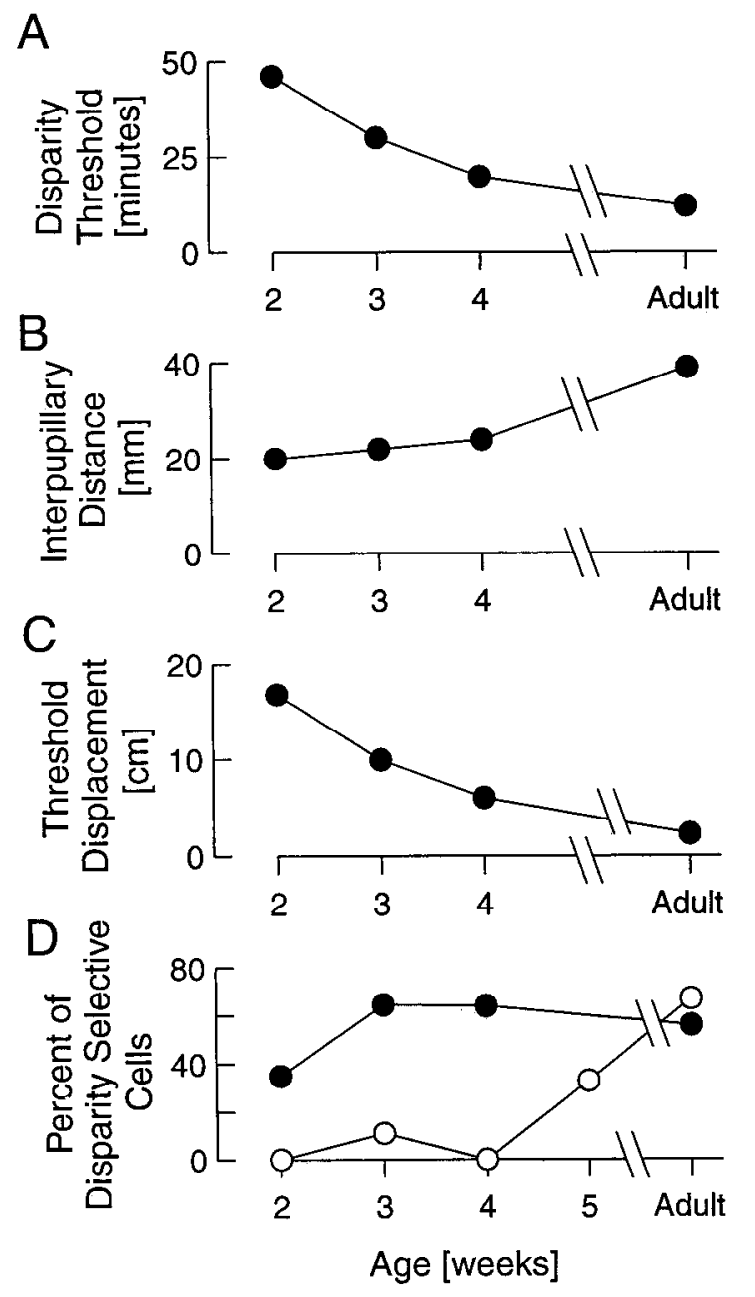

Figure 16. Predicted changes in binocular disparity thresholds (stereo acuity) are given here $(A-C)$ along with a comparison with previous data, of proportions of disparity-selective cells as a function of age $(D)$. $A$. Disparity thresholds are shown that correspond to a $90^{\circ}$ relative phase shift for a grating of spatial frequency $1 \mathrm{SD}$ higher than the mean. These values are predicted from the data presented in Figure $12 \mathrm{C}$ and plotted against postnatal age. This spatial frequency is one estimate of the highspatial-frequency cutoff for a population of neurons for each age group. $B$, Changes with age of interpupillary distance for the kitten and the cat, from Timney (1987), are plotted here. $C$, Predicted threshold displacements in depth, at a $50 \mathrm{~cm}$ fixation distance, are plotted against age The threshold displacement at each age is derived from values depicted in $A$ and $B . D$, Proportions of disparity-selective cells for kittens and cats are presented here. Data from this study (solid circles) are for phase-specific binocular responses, and the other data (open circles) are from a previous investigation (Pettigrew, 1974).

results (LeVay et al., 1978). Given this difficulty and the problem of physiological recording at 2 weeks, the present results are in general agreement with what is known from morphological work.

\section{Development of binocular depth perception}

Our results show that proportions of disparity-selective cells are relatively constant from postnatal age 3 weeks into adulthood. Of the factors that affect stimulus specificity (selectivity), only optimal spatial frequency continues to develop after 3 weeks postnatal (see Fig. 12C). The shift of the average optimal spatial frequency of a cell population to higher values causes reduction in the spatial offset that corresponds to a given change in relative phase. Since the visual system is able to make use of increasingly higher spatial frequencies as kittens grow, threshold disparities expressed in terms of spatial offset (e.g., in arc minutes) should decrease accordingly. This change is likely to be a primary aspect of the refinement of binocular disparity selectivity. With assumptions, one can make a prediction for changes in disparity threshold (stereo acuity) at each age. Figure 16 presents results of an attempt to do this. Assumptions are as follows. We assume that a $90^{\circ}$ shift in relative phase causes a sufficient change in the response that is detectable as a change in disparity. We also assume that cells that are tuned to relatively high spatial frequencies dictate stereo acuity. We therefore use the spatial frequency that is $1 \mathrm{SD}$ higher than the mean based on the results shown in Figure $12 C$. The spatial offset corresponding to a $90^{\circ}$ phase shift of this grating gives a predicted disparity threshold. These assumptions are arbitrary but are conservatively chosen. Therefore, results of these predictions should be interpreted as providing limits for possible performance, rather than as an attempt to pinpoint the exact values. These predicted disparity thresholds are plotted against age in Figure 16 $\mathrm{A}$. The predicted threshold decreases monotonically with age from 45 arc min at 2 weeks postnatal to about 12 arc min in adults.

The estimate of stereo acuity development expressed as actual threshold depth differences in real space (as opposed to the acuity expressed in angular units) also requires knowledge of changes in interpupillary distance with age. Figure $16 \mathrm{~B}$ replots interpupillary separation data obtained by Timney (1987). The interpupillary separation also continues to increase substantially after 4 weeks postnatal. With this change in interpupillary distance in mind, the expected developmental change in depth discrimination threshold in terms of physical displacement is given in Figure $16 C$. The values are obtained from data in Figure $16, A$ and $B$, for the viewing distance of $50 \mathrm{~cm}$. Because the changes in disparity threshold (Fig. 16A) and the increase in interpupillary distance (Fig. 16B) combine constructively, the rate of reduction in the displacement threshold shown in Figure $16 C$ is larger than that for disparity threshold expressed in arc minutes.

The data we have obtained permit an estimate of how relative proportions of disparity-selective cells vary with age. Neurons that exhibit phase-specific responses with dichoptic phase-varying stimulation are disparity selective. The proportions of cells in this category for kittens of 2,3 , and 4 weeks postnatal and for adults are $35 \%, 65 \%, 64 \%$, and $56 \%$, respectively. These results, shown in Figure $16 \mathrm{D}$, demonstrate an essentially flat function from 3 weeks on. Even at 2 weeks postnatal, a substantial fraction (35\%) of cells quantitatively studied are disparity selective. Considered together, these results show that the neural substrate for disparity selectivity and, presumably, stereoscopic depth discrimination is functional as early as one can reliably make the measurements from cortical cells in kittens.

Included in Figure $16 \mathrm{D}$ are data from a previous study in which estimates were made of disparity-selective cells in kittens at different ages (Pettigrew, 1974). These data are markedly different from our results. They show that there are virtually no disparity-selective cells in kittens at 2 and 4 postnatal weeks and only a few at week 3 . The proportion at 5 weeks is $33 \%$, and this compares with our finding of about $60 \%$, as interpolated from 3 and 4 week kittens (65\%) and adult data (56\%). Results for adults are quite similar (67\% vs $56 \%$ for our sample).

The tuning properties and non-neural considerations change so that disparity resolution increases during the first 2 postnatal months, but these appear as mainly a refinement. Our results 
differ substantially from those of Pettigrew (1974), who found no cells that were disparity selective at age 4 weeks postnatal (see Pettigrew, 1974, his Fig. 8). It is difficult to explain the discrepancy between his results and ours. One possibility is that the use of large, bright, sinusoidal gratings in our study enabled us to find and record responses that would not be exhibited with bars of light. We did not attempt to measure responses to changes in binocular disparity with stimuli other than gratings. Another possible contributing factor is the use in our study of quantitative techniques.

Given that cells are disparity selective at a very early age, it is of interest to know if behavioral data from kittens show similar results. Unfortunately, there are methodological problems such that behavioral data are not reliable until around 4 or more weeks postnatal. Tests with a jumping stand technique have been used to obtain data for threshold retinal disparities (Timney, 1981). These correspond to the smallest separation of grating targets in depth that can be discriminated. Results show some scatter, but overall there is a considerable developmental surge between postnatal days 30 and 40 . Thereafter, sensitivity levels off (Timney, 1981). Given the limits of the procedurc, disparity selectivity appears to be expressed behaviorally as early as it is possible to measure and peak values are also apparent soon after. The physiological results of our study also point to a similar conclusion; that is, the binocular apparatus for stereoscopic vision matures as early as it is feasible to measure reliably. There must, therefore, be an extensive genetic organization that underlies this function.

\section{References}

Albus K, Wolf W (1984) Early post-natal development of neuronal function in the kitten's visual cortex: a laminar analysis. J Physiol (Lond) 384:153-185.

Barlow HB, Pettigrew JD (1971) Lack of specificity of neurons in the visual cortex of young kittens. J Physiol (Lond) 218:98-100.

Barlow HB, Blakemore C, Pettigrew JD (1967) The neural basis of binocular depth discrimination. J Physiol (Lond) 193:327-342.

Bishop PO (1978) Orientation and position disparities in stereopsis. In: Frontiers in visual science (Cool SH, Smith EL, eds), pp 336-350. New York: Springer.

Bishop PO, Henry GH, Smith CJ (1971) Binocular interaction fields in the cat striate cortex. J Physiol (Lond) 216:39-68.

Blakemore C, Van Sluyters RC (1975) Innate and environmental factors in the development of the kitten's visual cortex. J Physiol (Lond) 248:663-716.

Blakemore C, Fiorentini A, Maffei L (1972) A second neural mechanism of binocular depth discrimination. J Physiol (Lond) 226:725749.

Blakemore C, Hawken MF, Mark RF (1982) Brief monocular deprivation leaves subthreshold synaptic input on neurones of the cat's visual cortex. J Physiol (Lond) 327:489-505.

Bonds AB (1979) Development of orientation tuning in the visual cortex of kittens. In: Developmental neurobiology of vision (Freeman RD, ed), pp 31-41. New York: Plenum.

Bonds AB, Freeman RD (1978) Development of optical quality in the kitten eye. Vision Res 18:391-398.

Braastad BO, Heggelund P (1985)Development of spatial receptivefield organization and orientation selectivity in kitten striate cortex. J Neurophysiol 53:1158-1178.

Callaway EM, Katz LC (1990) Emergence and refinement of clustered horizontal connections in cat striate cortex. J Neurosci 10:1134-1153.

Daniels JD, Pettigrew JD, Norman JL (1978) Development of single neuron responses in kitten's lateral geniculate nucleus. J Neurophysiol 41:1373-1393.

Derrington AM, Fuchs AF (1981) The development of spatial-frequency selectivity in kitten striate cortex. J Physiol (Lond) 316:1-10.

DeValois RL, Albrecht DG, Thorell LG (1982) Spatial frequency selectivity of cells in macaque visual cortex. Vision Res 22:545-559.

Ferster D (1981) A comparison of hinocular depth mechanisms in areas 17 and 18 of the cat visual cortex. J Physiol (Lond) 187:517552.

Fosse VM, Heggelund P, Fonnum F (1989) Postnatal development of glutamatergic, GABAergic, and cholinergic neurotransmitter phenotypes in the visual cortex, lateral geniculate nucleus, pulvinar, and superior colliculus in cats. J Neurosci 9:426-435.

Freeman RD, Lai CE (1978) Development of the optical surfaces of the kitten eye. Vision Res 18:399-407.

Freeman RD, Ohzawa I (1988) Monocularly deprived cats: binocular tests of cortical cells reveal functional connections from the deprived eye. I Neurosci 8:2491-2506.

Freeman RD, Olson C (1982) Brief periods of monocular deprivation in kittens: effects of delay prior to physiological study. J Neurophysiol 47:139-150.

Freeman RD, Robson JG (1982) A new approach to the study of binocular interaction in visual cortex: normal and monocularly deprived cats. Exp Brain Res 48:296-300.

Freeman RD, Mallach R, Hartley S (1981) Responsivity of normal kitten striate cortex deteriorates after brief binocular deprivation. J Neurophysiol 45:1074-1084.

Fregnac Y, Imbert M (1978) Early development of visual cortical cells in normal and dark-reared kittens: relationship between orientation selectivity and ocular dominance. J Physiol (Lond) 278:27-44.

Fregnac Y, Imbert M (1984) Development of neuronal selectivity in primary visual cortex of cat. Physiol Rev 64:325-434.

Hamasaki DI, Flynn JT (1977) Physiological properties of retinal ganglion cells of 3-week-old kittens. Vision Res 17:275-284.

Heggelund P, Albus K (1978) Response variability and orientation discrimination of single cells in cat striate cortex. Exp Brain Res 32: 197-211.

Henry GH, Dreher B, Bishop PO (1974) Orientation specificity of cells in cat striate cortex. J Neurophysiol 37:1394-1409.

Hicks TP (1984) The history and development of microiontophoresis in experimental neurobiology. Prog Neurobiol 22:185-240.

Hubel DH, Wiesel TN (1962) Receptive fields, binocular interaction and functional architecture in the cat's visual cortex. $J$ Physiol (Lond) 160:106-154.

Hubel DN, Wiesel TN (1963) Receptive fields of cells in striate cortex of very young, visually incxpcrienced kittens. J Ncurophysiol 26:9941002.

Ikeda H, Tremain KE (1978) The development of spatial resolving power of lateral geniculate neurones in kittens. Exp Brain Res 31: 193-206.

LeVay S, Voigt T (1988) Ocular dominance and disparity coding in cat visual cortex. Vis Neurosci 1:395-414.

LeVay S, Stryker MP, Shatz CJ (1978) Ocular dominance columns and their development in layer IV of the cat's visual cortex: a quantitative study. J Comp Neurol 179:223-244.

Levick WR (1972) Another tungsten microelectrode. Med Biol Eng 10:510-515.

Mitchell DE, Timney B (1984) Postnatal development of function in the mammalian visual system. In: Nervous system III. Handbook of physiology, Vol 3, Scc 1 (Darian-Smith I, cd), pp 507-555. Washington, DC: American Physiological Society.

Movshon JA, Thompson ID, Tolhurst DJ (1978) Spatial and temporal contrast sensitivity of neurones in areas 17 and 18 of the cat's visual cortex. J Physiol (Lond) 283:101-120.

Nelson JI, Kato H, Bishop PO (1977) Discrimination of orientation and position disparities by binocularly activated neurons in cat striate cortex. J Neurophysiol 40:260-283.

Ohzawa I, Freeman RD (1986a) The binocular organization of simple cells in the cat's visual cortex. J Neurophysiol 56:221-242.

Ohzawa I, Freeman RD (1986b) The binocular organization of complex cells in the cat's visual cortex. J Neurophysiol 56:243-259.

Ohzawa I, Freeman RD (1988) Binocularly deprived cats: binocular tests of cortical cells show regular patterns of interaction. J Neurosci 8:2507-2516.

Olson C, Freeman RD (1978) Monocular deprivation and recovery during sensitive period in kittens. J Neurophysiol 41:65-74.

Pettigrew JD (1974) The effect of visual experience on the development of stimulus specificity by kitten cortical neurons. J Physiol (Lond) 237:49-74.

Ramoa A, Shadlen M, Freeman RD (1987) Dark-reared cats: unresponsive cells become visually responsive with microiontophoresis of an excitatory amino acid. Exp Brain Res 65:658-665. 
Rodieck RS, Pettigrew JD, Bishop PO, Nikara T (1967) Residual eye movements in receptive field studies of paralyzed cats. Vision Res 7: $107-110$.

Rusoff AC, Dubin MW (1977) Development of receptive field properties of retinal ganglion cells in kittens. J Neurophysiol 40:11881198.

Sherk H, Stryker MP(1976) Quantitative study of cortical orientation selectivity in visually inexperienced kitten. J Neurophysiol 39:63-70.

Sherman SM (1972) Development of interocular alignment in cats. Brain Res 37:187-203.

Skottun BC, DeValois RL, Grosof DH, Movshon JA, Albrecht DG, Bonds AB (1991) Classifying simple and complex cells on the basis of response modulation. Vision Res 31:1079-1086.

Thorn F, Gollender M, Erickson P (1976) The development of the kitten's visual optics. Vision Res 16:1145-1150.
Timney B (1981) The development of binocular depth perception in kittens. Invest Ophthalmol Vis Sci 21:493-496.

Timney B (1987) The development of depth perception. In: Advances in neural and bchavioral development, Vol 3 (Shinkman P, ed), pp 153-207. Norwood, NJ: Ablex.

Tootle JS (1991) Early postnatal development of visual function in kitten retinal ganglion cells. Invest Ophthalmol Vis Sci [Suppl] 32: 1043.

Tsumoto T, Suda K (1982) Laminar differences in development of afferent innervation to striate cortex neurones in kittens. Exp Brain Res 45:433-446.

Watkins DW, Berkley MA (1974) The orientation selectivity of single neurons in cat striate cortex. Exp Brain Res 19:433-446. 